\title{
Validation of the Earth radiation budget as simulated by the Max Planck Institute for Meteorology general circulation model ECHAM4 using satellite observations of the Earth Radiation Budget Experiment
}

\author{
C.-T. Chen ${ }^{1}$ and Erich Roeckner \\ Max Planck Institute for Meteorology, Hamburg, Germany
}

\begin{abstract}
In this study, the Earth radiation budget as simulated by the latest version of the ECHAM general circulation model (ECHAM4) is documented. The Earth radiation budget obtained from the model is evaluated through comparison with Earth Radiation Budget Experiment (ERBE) data. The model simulations generally agree with the satellite-observed spatial distribution and seasonal variation of the radiation budget. The interannual variabilities of the simulated radiative quantities in the tropics are also comparable to the observed data. There are, however, biases in the details. The longitudinal structure of the radiation fields in the tropics is not exactly reproduced. The slight differences in the geographical location of the various radiation quantities are related to the errors in the simulation of the tropical east-west longitudinal circulation and associated cloud fields. The most significant bias in the radiation budget is the simulated shortwave radiative effect from cloud. Consistent underestimation in the shortwave cloud radiative forcing is found over the midlatitude oceans in summer. This bias is due to an underestimation in the total cloud amount. In the tropics the simulated shortwave cloud radiative forcing is persistently larger than that derived from ERBE data. The systematic overestimation in the shortwave cloud radiative forcing at various values of the longwave cloud radiative forcing suggests that this problem is related to the neglect of sub-grid-scale cloud water content variability and its effect on the grid-averaged shortwave radiative flux. Although the tropical interannual variability of cloud radiative forcing is reasonably well reproduced by the model, the major contribution for the simulated anomalies is from the cloud water anomalies, while observations suggest the dominant factor is the total cloud cover anomalies. Lack of observations for various cloud parameters limits the attempt of further validation.
\end{abstract}

\section{Introduction}

Sunlight, reflected solar radiation, and emitted terrestrial radiation are the climate system's primary sources and sinks of energy. The spectrally dependent optical properties of the atmosphere and the Earth's surface, variable at a variety of time and space scales, further complicate the spatial and temporal distribution of the Earth's energy budget. The space-time variation of the difference between the absorbed solar radiation and the outgoing longwave radiation (OLR) then provides the fundamental energy source for driving the atmospheric circulation. Thus an accurate simulation of the geographic distribution and seasonal variation of the incoming and outgoing radiant energy is one of the basic requirements for an atmospheric general circulation model (GCM) to reproduce the present climate. Since the prime determinant of the radiation field in the atmosphere is cloud [London, 1957; Ohring and Clapp, 1980; Ramanathan et al., 1989], it is therefore also vital for the model to realistically simulate the temporal and spatial distribution of clouds and their radiative

'Now at Department of Earth Sciences, National Taiwan Normal University, Taipei.

Copyright 1996 by the American Geophysical Union.

Paper number 95JD03195.

0148-0227/96/95JD-03195\$05.00 impact. However, it is recognized [e.g., Intergovernmental Panel on Climate Change (IPCC), 1992] that the highly parameterized cloud processes and the resulting cloud-climate interactions represent one of the main uncertainties in climate modeling [Cess et al., 1990; Gates, 1992]. In this study we document the Earth radiation budget simulated by the fourth generation atmospheric GCM developed at the Max Planck Institute for Meteorology in Hamburg (ECHAM4) and investigate the underlying physical processes and parameterization issues that lead to the resulting temporal and spatial distribution of the radiation fields.

In recent years, satellite measurements have increasingly been used as an important validation tool for GCMs [e.g., Hartmann et al., 1986; Gurney et al., 1993]. For the Earth's radiation budget, the high instrument accuracy and the temporal and spatial sampling capacities of the Earth Radiation Budget Experiment (ERBE) [Barkstrom, 1984] provide a unique data set that surpasses previous attempts in measuring the global radiation distribution. Hence ERBE data are used to evaluate the Earth radiation budget simulated by ECHAM4. The outline of this paper is as follows: Section 2 describes the model simulation and observational data used in the comparison and offers a brief description of ECHAM4 physical parameterizations which are particularly relevant to the simulation of Earth radiation budget. Section 3 presents the comparison of the ERBE and ECHAM4 data. We consider 
global averages, zonal means, and geographical distribution of the radiative fluxes. The seasonal cycle of the Earth radiation budget, the regional analyses of statistics of longwave versus shortwave radiative fields, and the interannual variability over the tropical region are also included in the comparison, and possible sources of the model errors are discussed. Section 4 summarizes the findings.

\section{Data Sets}

\subsection{ERBE}

The ERBE observation provides monthly data on a $2.5^{\circ}$ by $2.5^{\circ}$ grid. The quantities used in the present comparison are OLR, planetary albedo, clear-sky OLR, and total and clear-sky net solar fluxes at the top of the atmosphere. A detailed description of the data processing and products is given by Barkstrom [1984], ERBE Science Team [1986], and Ramanathan et al. [1989]. The estimated uncertainty in the fluxes is $\sim 10 \mathrm{~W} / \mathrm{m}^{2}$. There are a few regions where clear-sky fluxes are not available. Because of the permanent occurrence of cloud these areas did not meet the cloud-free criteria in the data processing. It should also be noted that there are difficulties in estimating clear-sky flux over regions covered with sea ice and snow due to the cloud detection problem. Thus the clear-sky data are less reliable poleward of $60^{\circ}$ north and south. Nevertheless, one of the advantages in using the ERBE data is the existence of the retrieved clear-sky radiative fluxes. One can then define a cloud radiative forcing as the difference between clear-sky and total radiative fluxes to assess the impact of cloud on the radiation budget [Ramanathan, 1987; Cess and Potter, 1987; Ramanathan et al., 1989]. In the longwave, cloud radiative forcing is defined as

$$
\mathrm{LWCF}=F_{\mathrm{cir}}-F_{\text {tot }}
$$

where $F_{\text {clr }}$ is the clear-sky OLR and $F_{\text {tot }}$ is the OLR. Longwave cloud radiative forcing is a positive quantity, since the clear-sky OLR is, in general, larger than the total OLR. This implies that clouds tend to warm the surface-atmosphere system in the longwave. In the shortwave spectral region the cloud radiative forcing is defined as

$$
\mathrm{SWCF}=S_{\mathrm{tot}}-S_{\mathrm{clr}}
$$

where $S_{\text {tot }}$ is the net solar flux at the top of the atmosphere and $S_{\text {clr }}$ is the clear-sky net solar flux at the top of the atmosphere. Since, under identical conditions, a cloudy atmosphere reflects a larger part of the incoming solar radiation than a clear-sky atmosphere, $S_{\text {tot }}$ is, in general, smaller than $S_{\text {clr. }}$. Therefore in the shortwave, clouds act to cool the surface-atmosphere system.

Monthly mean radiative quantities from ERBE between February 1985 and January 1989 are used to derive ensemble averages for monthly and annual mean data. Missing clear-sky fluxes only exist when the missing clear-sky fluxes at a specific grid point are detected in all four years. Otherwise, the average of the available data is provided. As discussed by Kiehl et al. [1994], though the missing data regions may raise some concerns for the comparison, the actually involved area is sufficiently small so that the derived cloud radiative forcing is still an acceptable diagnostic tool to evaluate the model simulation.

\subsection{Model}

The ECHAM atmospheric GCM has evolved from the spectral numerical weather forecasting model of the European
Centre for Medium-Range Weather Forecasts and has been modified extensively at the Max Planck Institute for Meteorology in Hamburg for climate applications. The fourth generation ECHAM model (ECHAM4) incorporates the most recent improvements in physical representation of a wide range of key climate processes. Cloud and radiation, moisture transport, convection, cloud-turbulence interaction in the planetary boundary layer, and land surface data are the major processes under revision compared to the previous version (ECHAM3, Roeckner et al. [1992]). These changes have direct impacts on the simulation of the Earth radiation budget. A detailed description of the dynamical and physical structure and the simulated climatology of ECHAM4 is documented by E. Roeckner et al. (manuscript in preparation, 1995 (hereinafter referred to as ER95). The main characteristics of the model and the employed physical parameterizations for cloud and radiation are summarized as follows:

The prognostic variables in ECHAM4 include vorticity, divergence, temperature, surface pressure, water vapor, and cloud water. The standard resolution of the model is T42 (approximately $2.8^{\circ}$ by $2.8^{\circ}$ in longitude and latitude) with 19 hybrid vertical levels (top at $10 \mathrm{hPa}$ ). Both annual and diurnal cycles are included. Semi-implicit, leapfrog time integration scheme with a 24-min time step is used for the simulation with T42 resolution. The radiation fluxes are calculated every 2 hours. A semi-Lagrangian transport method is used for the advection of moisture and cloud water [Williamson and Rasch, 1989].

A new radiation code [Fouquart and Bonnel, 1980; Morcrette, 1991] replaces the old radiation scheme [Hense et al., 1982] used in ECHAM3. Two- and six-band intervals are used in the solar $(0.25-4 \mu \mathrm{m})$ and terrestrial (between 0 and $2620 \mathrm{~cm}^{-1}$ ) part of the spectrum, respectively. There are the following further modifications in the new code: (1) additional greenhouse gases $\left(\mathrm{CH}_{4}, \mathrm{~N}_{2} \mathrm{O}, \mathrm{CFCs}\right.$, and 14.6- $\mu \mathrm{m} \mathrm{O} \mathrm{O}_{3}$ band) are included; (2) the single-scattering properties of cloud water droplets and ice crystals are parameterized according to Rockel et al. [1991], i.e., calculated from Mie theory for droplets and ice crystals and adapted to the broadband model. The asymmetry factor for ice is adjusted to account for the nonsphericity of ice crystals. The effective radii of cloud droplets are parameterized from cloud water content. The number concentration of cloud droplets are specified $\left(100\right.$ and $220 \mathrm{~cm}^{-3}$ are assigned to the low-level maritime and continental clouds, respectively, and gradually reduced to $50 \mathrm{~cm}^{-3}$ in the upper layers). Spherical shape is assumed for all liquid cloud droplets. The effective radii of ice crystals are functions of the ice water content based on empirical data [Heymsfield, 1977; McFarlane et al., 1992]; (3) water vapor continuum is modified to include temperatureweighted band averages of $e$-type continuum absorption and band-dependent ratio of (p-e)-type to $e$-type continuum absorption [Giorgetta and Wild, 1995]; (4) a Voigt line shape correction is applied in the stratosphere. The maximum cloud overlap assumption is used for contiguous cloud layers. Otherwise, random overlap is assumed.

The vertical turbulent transfer of momentum, heat, water vapor, and cloud water is based on the Monin-Obukhov similarity theory for the surface layer and the eddy diffusivity approach above the surface layer [Louis, 1979]. The drag and heat transfer coefficients depend on roughness length and $\mathrm{Ri}$ chardson number. The first-order turbulence closure scheme in ECHAM3 is replaced by a turbulent kinetic energy closure 
Table 1. Global Mean Top-of-Atmosphere Earth Radiation Budget Quantities From ECHAM4 and ERBE for Annual, January, and July Average

\begin{tabular}{lccccccr}
\hline & \multicolumn{3}{c}{ ECHAM4 } & & \multicolumn{3}{c}{ ERBE } \\
\cline { 2 - 3 } \multicolumn{1}{c}{ Variable } & Annual & January & July & & Annual & January & July \\
\hline OLR $\left(\mathrm{W} / \mathrm{m}^{2}\right)$ & 235.2 & 232.7 & 238.8 & & 235.3 & 232.8 & 239.3 \\
$S_{\text {trt }}\left(\mathrm{W} / \mathrm{m}^{2}\right)$ & 236.9 & 241.6 & 230.8 & & 240.3 & 245.2 & 236.4 \\
Albedo $^{\text {OLR }}$ & 0.31 & 0.31 & 0.30 & & 0.30 & 0.30 & 0.29 \\
$S_{\text {clr }}\left(\mathrm{W} / \mathrm{m}^{2}\right)$ & 263.9 & 260.8 & 268.2 & & 264.2 & 261.4 & 268.5 \\
LWCF $\left(\mathrm{W} / \mathrm{m}^{2}\right)$ & 286.2 & 295.2 & 278.9 & & 289.0 & 296.9 & 283.9 \\
SWCF $\left(\mathrm{W} / \mathrm{m}^{2}\right)$ & 28.7 & 28.1 & 29.4 & & 28.9 & 28.6 & 29.2 \\
\hline
\end{tabular}

ERBE, Earth Radiation Budget Experiment; OLR, outgoing longwave radiation.

with the Prandtl-Kolmogorov parameterization of eddy diffusivity [Brinkop and Roeckner, 1995].

The mass flux scheme for deep, shallow, and midlevel convection [Tiedtke, 1989] has been modified with respect to the closure for penetrative convection and the formulation of organized entrainment and detrainment [Nordeng, 1995]. The deep convection closure depends on convective instability (CAPE) instead of the moisture convergence of Tiedtke [1989]. Cumulus clouds are represented by a bulk model including the effect of entrainment (organized and turbulent) and detrainment (mostly through organized outflow at cloud top) on the updraft and downdraft convective mass fluxes. Organized entrainment depends on local buoyancy and organized detrainment is derived for a spectrum of clouds [Nordeng, 1995]. The detrained fraction of the convectively generated cloud water is coupled with the stratiform (anvil) cloud water equation. Shallow and midlevel convection depend on surface evaporation and large-scale vertical velocity, respectively.

The prediction of stratiform clouds is based on the cloud water transport equation, including sources and sinks due to condensation/evaporation and precipitation formation by coalescence of cloud droplets and sedimentation of ice crystals [Sundquist, 1978; Roeckner et al., 1991]. Evaporation of cloud water and precipitation is considered. Sub-grid-scale condensation and cloud formation is taken into account by specifying height-dependent thresholds of relative humidity [Xu and Krueger, 1991; Walcek, 1994]. The same threshold is applied to both convective and stratiform cloud. The liquid, ice, and mixed-phase clouds are diagnosed according to ambient temperature [Matveev, 1984; Roeckner et al., 1991].

A new global data set of land-surface parameters is used [Claussen et al., 1994]. These parameters, including surface background albedo, surface roughness length, leaf area index, fractional vegetation cover, and forest ratio, are constructed from the major ecosystem complex of Olson et al. [1983]. There is a temperature dependence of ice and snow albedo [Robock, 1980 ], and snow albedo is also a function of the fractional forest area.

The model data are obtained from a 15-year integration prescribing observed monthly mean sea surface temperature (SST) and sea ice data from 1979 to 1993 as surface boundary forcing. However, unless mentioned elsewhere, the model results reported in this study are generally derived from a 10-year subensemble of annual and monthly means from 1979 to 1988 which is the reference period of the so-called Atmospheric Model Intercomparison Project (AMIP) data set [Gates, 1992]. The clear-sky fluxes from ECHAM4 are compiled using method II as referred by Cess and Potter [1987]; that is, the model computes clear-sky fluxes at each grid point by setting the cloud amount to zero in an additional call to the radiation routine. Strictly speaking, there is a difference between the clear-sky flux from ERBE and the model. While ERBE clearsky fluxes are averages only over the cloud-free region, ECHAM clear-sky fluxes, on the other hand, represent averages over both clear and overcast portions. A detailed study on different approaches to compute clear-sky fluxes from GCMs [e.g., Zhang et al., 1994] shows that the estimated bias in clearsky flux using method II is around $10 \mathrm{~W} / \mathrm{m}^{2}$ in persistently cloudy regions. However, for most other areas the error should be smaller.

\section{Comparison of Model Results and Satellite Data}

\subsection{Global Means}

Global mean top-of-atmosphere radiative fluxes and cloud radiative forcing for annual averages are listed in Table 1. They are derived from the mean values of 4-year ERBE data and 10 -year model integration. The ensemble mean of globally and annually averaged total cloud cover generated by the model is 0.60 , which is slightly less than the 0.62 as derived from the International Satellite Cloud Climatology Project (ISCCP) [Schiffer and Rossow, 1985; Rossow and Lacis, 1990]. According to ERBE the annual and global mean heating by absorbed shortwave radiation $S_{\text {tot }}$ is $5 \mathrm{~W} / \mathrm{m}^{2}$ larger than the heat loss by outgoing longwave radiation (OLR). This imbalance is smaller in ECHAM4 $\left(1.7 \mathrm{~W} / \mathrm{m}^{2}\right)$, mainly due to $S_{\text {clr }}$ which is about 3 $\mathrm{W} / \mathrm{m}^{2}$ smaller than that of ERBE. The good agreement between the simulated and the observed annual mean LWCF and SWCF is the result of cloud microphysical parameter tuning.

The same radiative quantities for January and July ensemble averages from ECHAM4 and ERBE are also listed in Table 1. The ensemble January and July global mean total cloud cover is 0.62 and 0.59 , respectively. The corresponding total cloud cover according to ISCCP data is 0.62 in both January and July. The seasonal change in total and clear-sky OLR in ECHAM4 is similar to the observed variation. Consequently, good agreement in LWCF is to be expected. In both months the absorbed solar fluxes are smaller in the model simulation. The difference is slightly larger in July. Similarly, the clear-sky absorbed solar flux is smaller in the model. The global mean net radiation imbalances in the model are 8.9 and $-8.0 \mathrm{~W} / \mathrm{m}^{2}$ for January and July, respectively, while they are 12.4 and $-2.9 \mathrm{~W} / \mathrm{m}^{2}$ in the ERBE data. 


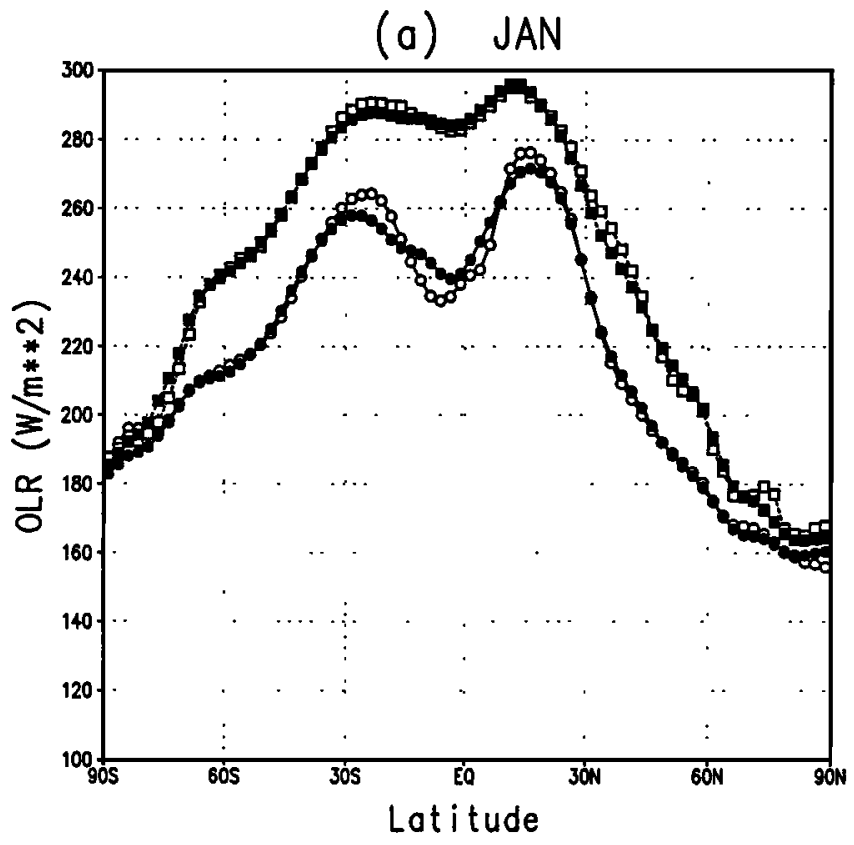

(b) JUL

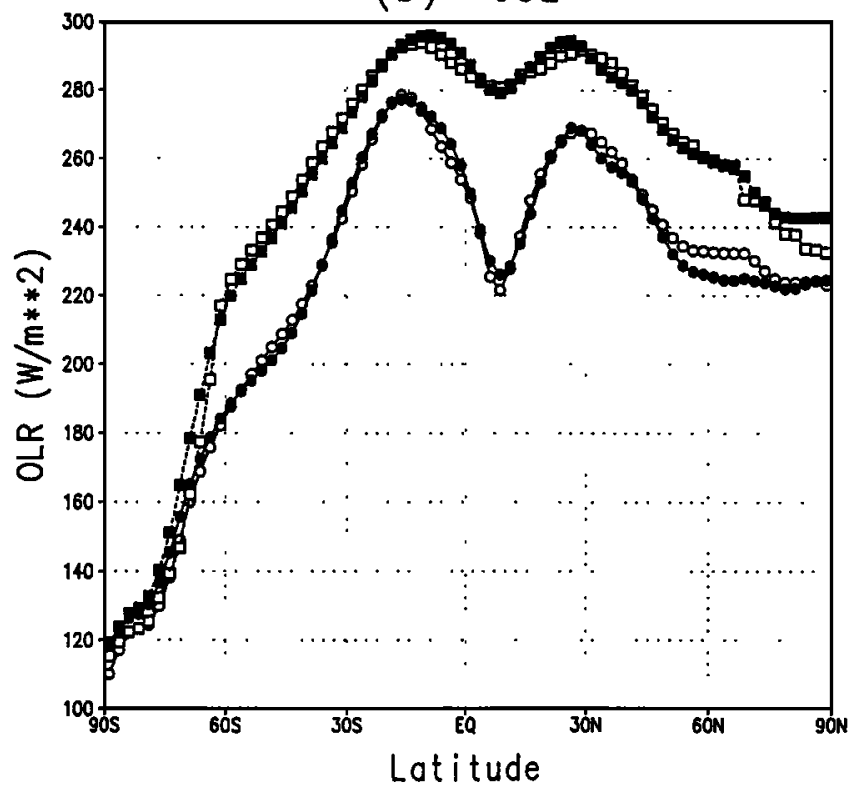

Figure 1. Ensemble mean of zonally averaged outgoing longwave radiation (circles) and clear-sky outgoing longwave radiation (squares) from the Earth Radiation Budget Experiment (ERBE) (open) and ECHAM4 (solid) for (a) January and (b) July.

\subsection{Zonal and Geographic Comparisons}

The zonally averaged total and clear-sky OLR for January and July from ERBE and ECHAM4 are shown in Figures 1a and $1 b$. In January, OLR in ECHAM4 agrees well with that in ERBE over the midlatitudes. In the tropics, ECHAM4 overestimates the OLR near the equator and underestimates the OLR in the subtropics. However, the differences are generally less than $10 \mathrm{~W} / \mathrm{m}^{2}$. The overestimate of OLR near the equator is caused probably by too transparent high clouds. In July the model is in excellent agreement with ERBE at most latitudes, except near $60^{\circ} \mathrm{N}$ where an underestimate, contributed mostly from the oceanic storm track regions, is found in the model. Except at high latitudes the simulated clear-sky OLR is in excellent agreement with ERBE data. However, one should keep in mind that because of the problem of scene identification in areas covered with ice and snow, the observed clear-sky data poleward of $60^{\circ}$ is less reliable.

The geographic distributions of OLR for January and July from ERBE and ECHAM4 are shown in Figures 2a-2d. In January, according to ERBE, the low OLR (less than 220 $\mathrm{W} / \mathrm{m}^{2}$ ) regions in the tropics are closely connected with the location of the Intertropical Convergence Zone (ITCZ), the South Pacific Convergence Zone (SPCZ), and the Congo and Amazon River basins characterized by deep convective activity. In the subtropics the OLR maxima are linked to the dry and warm subsidence regions as it is clearly shown in ERBE data. The OLR in high latitudes is generally smaller than that in the tropics. The main pattern of the geographical distribution is well captured by ECHAM4. There are, however, differences in the details. The OLR over the Congo and Amazon river basins is larger in the model by more than $20 \mathrm{~W} / \mathrm{m}^{2}$. Different from ERBE data which show OLR minima over the maritime continent (Indonesia and surrounding areas), the model generates two centers with low OLR in the western Pacific and Indian Ocean, respectively. Also, ECHAM4 pro-
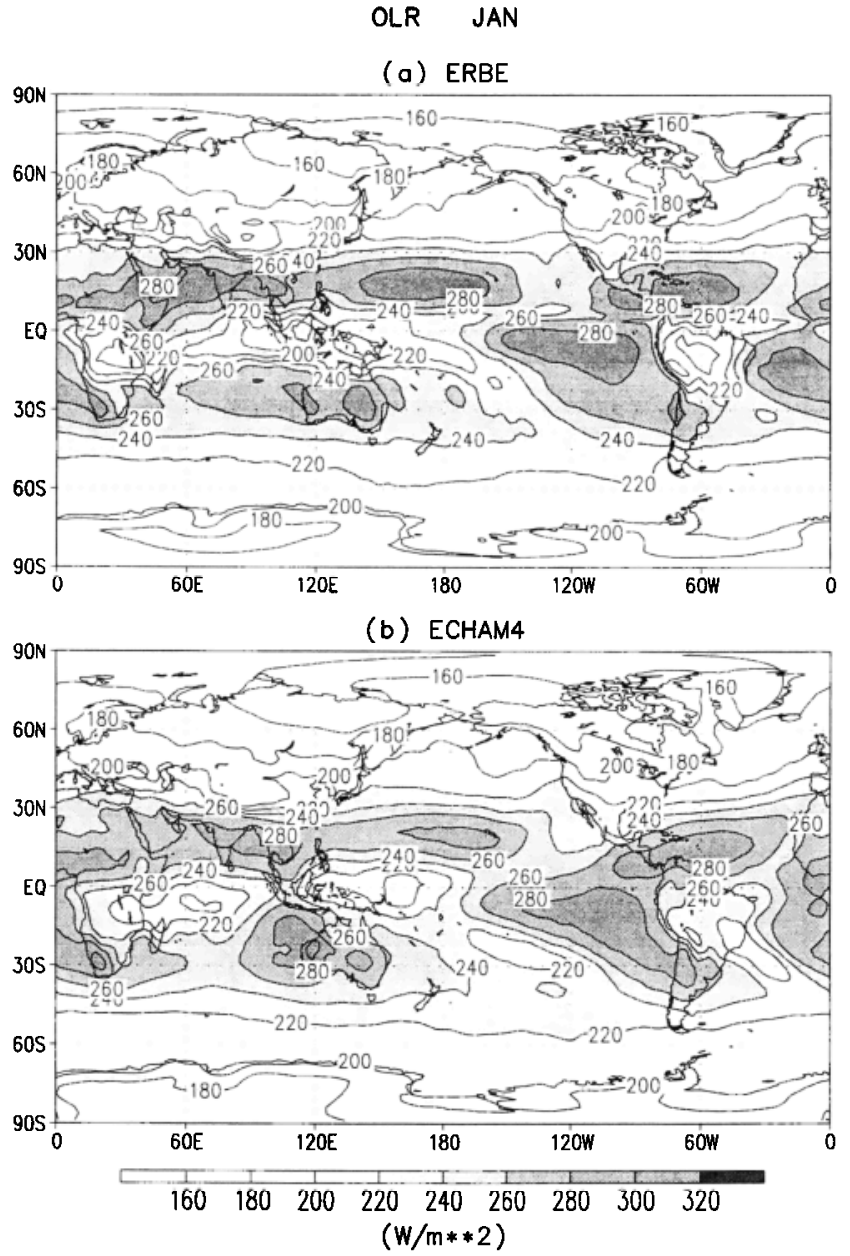

Figure 2. Geographic distribution of ensemble mean outgoing longwave radiation for (a) January ERBE, (b) January ECHAM4, (c) July ERBE, and (d) July ECHAM4. 
duces smaller OLR, in general, over the SPCZ and the South Atlantic Convergence Zone (SACZ). Differences in the midlatitudes are typically less than $5 \mathrm{~W} / \mathrm{m}^{2}$. In July the ITCZ resides to the north of the equator across the Pacific and the Atlantic as indicated by the low OLR in the ERBE data. Also the seasonal northward migration of the main convective centers is evident by the observed low OLR in both Central Africa and Central America. The extremely dry and warm Arabian Peninsula and Sahara Desert produce OLR greater than 300 $\mathrm{W} / \mathrm{m}^{2}$, while the storm track over the northern Pacific is characterized by relatively low OLR. Again, all these major features are reproduced in ECHAM4, but there are differences in certain regions. The OLR minima over the maritime continent and Central America are more pronounced in ECHAM4 than in the ERBE observation by more than $30 \mathrm{~W} / \mathrm{m}^{2}$. While ERBE data show the lowest OLR located over the Bay of Bengal as a result of the monsoonal circulation, the simulated OLR minima are shifted southeastward with the center over Malaysia. The OLR in the southwestern United States is overestimated, and the region of larger OLR extends too far southward to the equator. The simulated OLR is too low, on the other hand, in the western part of the North Atlantic and North Pacific, respectively.

The zonally averaged total and clear-sky planetary albedo for January and July from ECHAM4 and ERBE is shown in Figures $3 \mathrm{a}$ and $3 \mathrm{~b}$. In the summer hemisphere the simulated
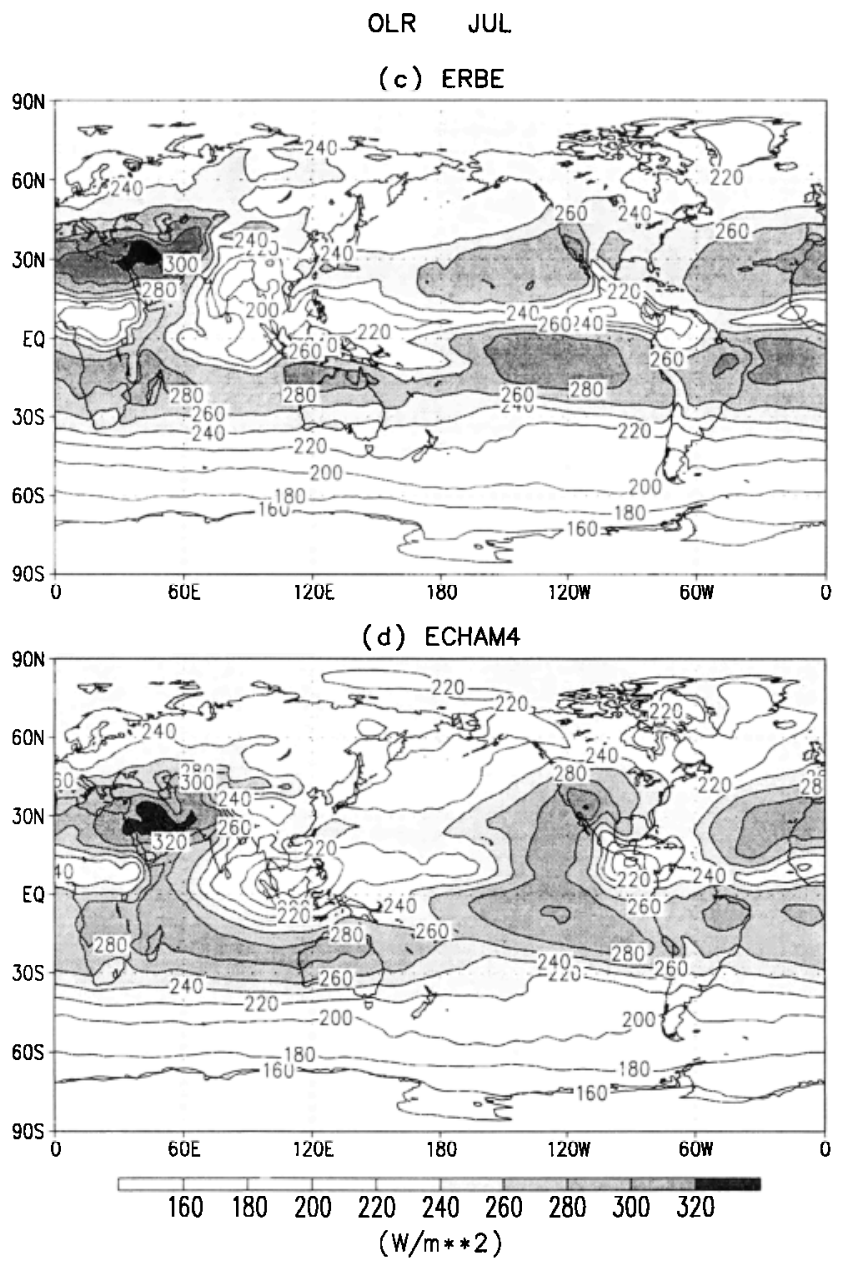

Figure 2. (continued)

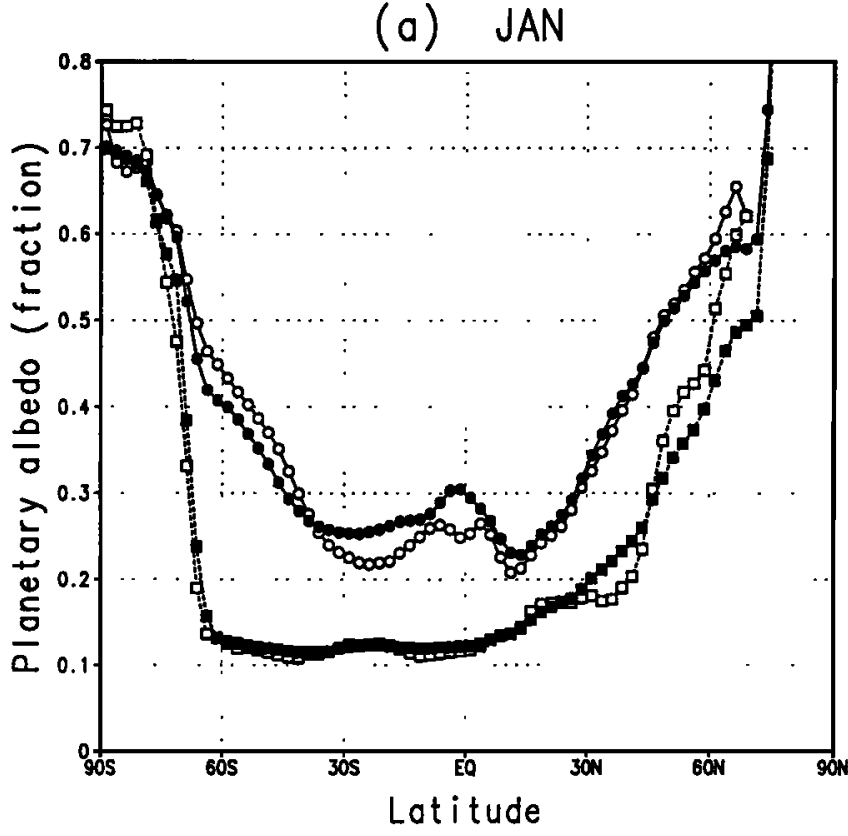

(b) JUL

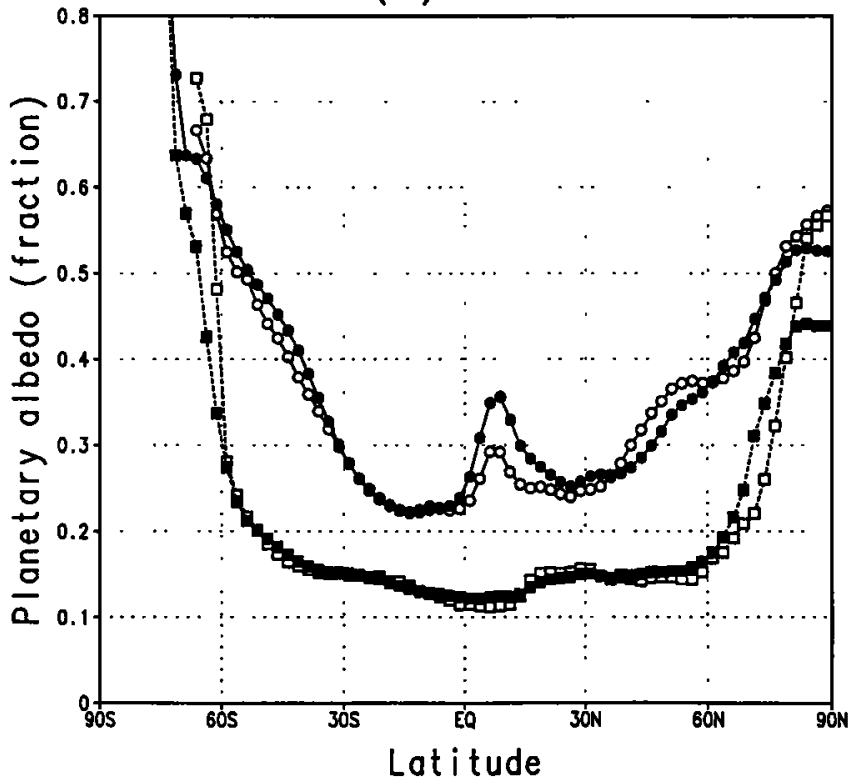

Figure 3. Ensemble mean of zonally averaged planetary albedo (circles) and clear-sky planetary albedo (squares) from ERBE (open) and ECHAM4 (solid) for (a) January and (b) July.

albedo is generally too high in the tropics, while it is too low in midlatitudes. A better agreement between model and ERBE is found in the respective winter hemisphere. Equatorward of $60^{\circ}$ the simulated clear-sky albedo generally agrees well with ERBE. One exception is in the northern hemisphere midlatitudes in January where the simulated clear-sky albedo is too large between $30^{\circ} \mathrm{N}$ and $40^{\circ} \mathrm{N}$, while it is lower than observed poleward of about $50^{\circ} \mathrm{N}$ (Figure 3a). Since corresponding differences are not found in July (Figure $3 \mathrm{~b}$ ), the most likely cause for the discrepancy in January is too extensive snow cover and/or too high snow albedo over the Himalayas and less 


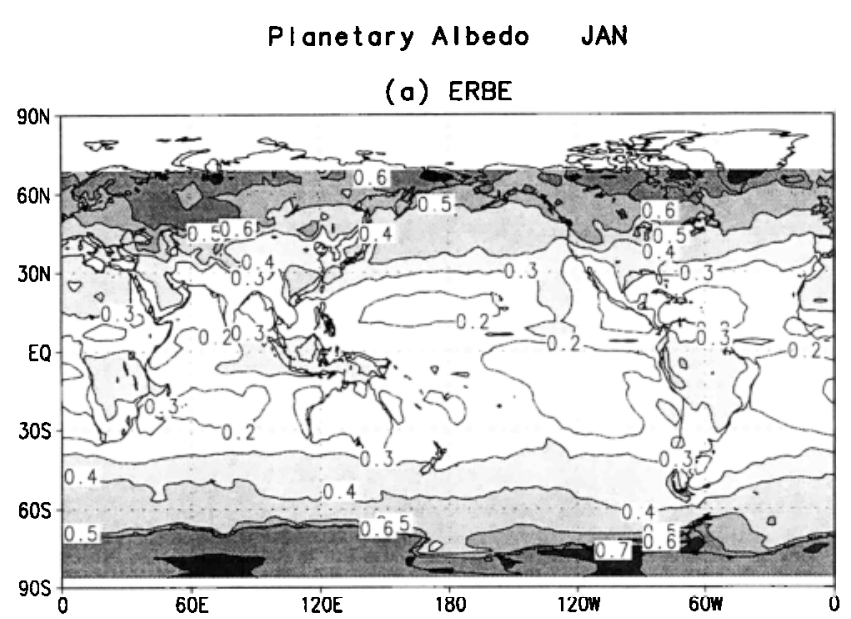

(b) ECHAM4

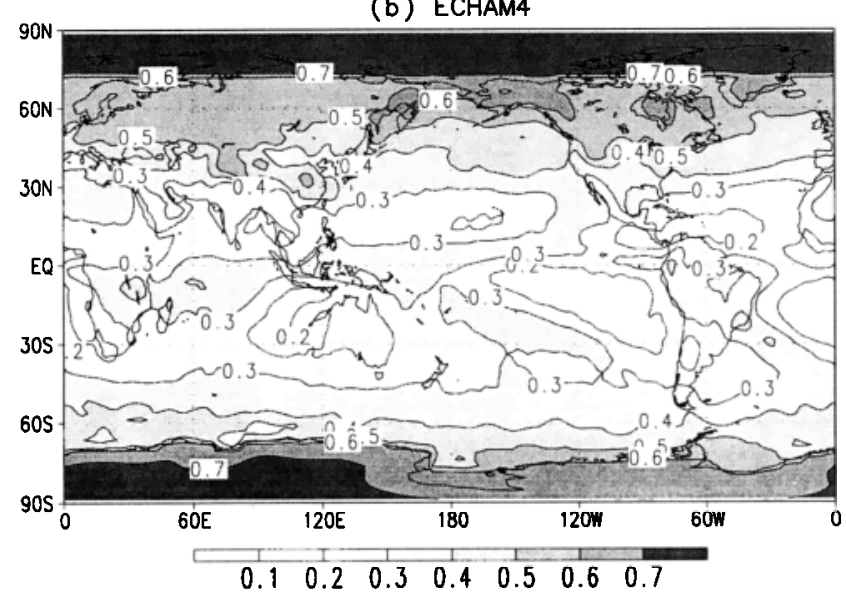

Figure 4. Geographic distribution of ensemble mean planetary albedo for (a) January ERBE, (b) January ECHAM4, (c) July ERBE, and (d) July ECHAM4.

extensive snow and/or too small snow albedo poleward of $50^{\circ} \mathrm{N}$.

Figures $4 a-4 d$ show the January and July geographic distribution of planetary albedo from the model and ERBE. The January albedo simulated by ECHAM4 is overestimated over the deep convective regions in the tropics. The high ERBE albedo in the subtropics off the west coast of California, South America, and southern Africa is related to the presence of marine stratocumulus cloud. ECHAM4 also captures these features except for the cloud regime off the west coast of South America which is not well reproduced in the model. There is a general underestimate of planetary albedo over the Southern Ocean, most likely caused by an underestimate of low cloud amount.

In July an overestimate of planetary albedo is found in the location of the ITCZ and also in the western half of the northern hemisphere ocean basins. The simulated marine stratocumulus regime off the west coast of the continents is indicated by local maxima in planetary albedo, but the magnitude is generally smaller than ERBE data suggest. There are underestimates of planetary albedo in the northern hemisphere midlatitudes, especially over the storm track regions, related probably to an underprediction of low cloud amount.

Next, we will illustrate the radiative effect of clouds by examining the distribution of cloud radiative forcing. The model- generated geographic distribution of total cloud cover in January and July is shown in Figures 5a and 5b, respectively. The corresponding January and July total cloud cover observations (averaged from 1984 to 1990) from ISCCP data are shown in Figures $5 \mathrm{c}$ and $5 \mathrm{~d}$, respectively. Note that the time span for the different data sets is not the same. Hence there might be an influence on the differences between model and observations from interannual variability in cloud cover. In addition, large differences between the available observed cloud climatologies have also been reported [Mokhov and Schlesinger, 1994]. The problem of intersatellite calibration in cloud detection is also evident in ISCCP data (cf. Figures 5c and 5d). Thus one should cautiously interpret a strict pointwise comparison for the cloud amount. The purpose of the illustration here is limited to providing a reference for the later discussion of radiative impact from cloud. A more detailed evaluation of simulated cloud parameters is the subject of a forthcoming study. The simulated January and July geographical distributions of total cloud water path are shown in Figures $6 \mathrm{a}$ and $6 \mathrm{~b}$. The zonally averaged vertical distribution of cloud fraction and cloud water content are illustrated in Figures 7 and 8, respectively. Note that cloud water content includes ice and liquid water. We will not discuss these cloud fields in detail. Further, a reliable cloud climatology to test against the vertical cloud distribution and microphysical properties is not yet available. However, the representation of the simulated cloud fields would be useful

Planetary Albedo JUL

(c) ERBE

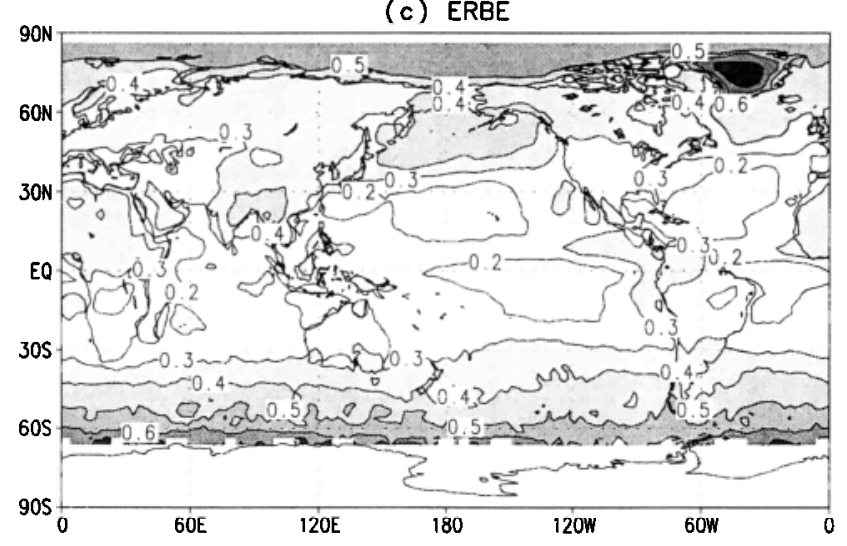

(d) ECHAM4

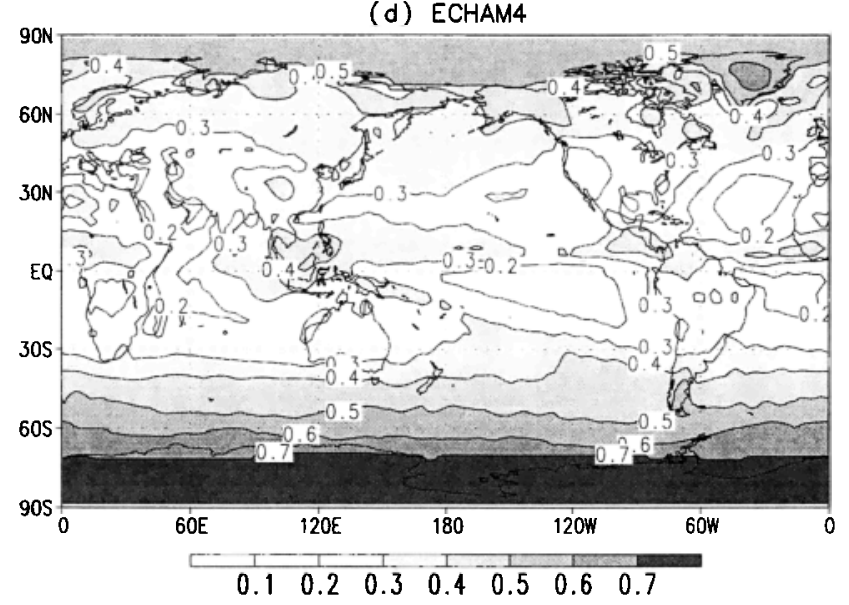

Figure 4. (continued) 
information for the following investigation of the simulated cloud radiative forcing in ECHAM4.

Figures $9 \mathrm{a}$ and $9 \mathrm{~b}$ show the zonal averages of LWCF equatorward of $60^{\circ}$ from ERBE and ECHAM4 for January and July, respectively. The latitudinal structure of LWCF from ECHAM4 is in good agreement with ERBE data, and the model bias is below $10 \mathrm{~W} / \mathrm{m}^{2}$ everywhere. Similar to OLR (cf. Figure 1), the errors are larger in January than in July with the largest underestimate of about $8 \mathrm{~W} / \mathrm{m}^{2}$ near $10^{\circ} \mathrm{S}$ and a similar error at $40^{\circ} \mathrm{N}$.

Figures 10a-10d show the longwave cloud radiative forcing from ERBE and ECHAM4 for January and July, respectively. Note that there are areas of missing data in ERBE observation. As noted above, ERBE data are less reliable poleward of about $60^{\circ}$. One can notice that most of the model errors in the previously discussed OLR distribution are mainly due to the radiative flux simulation in the cloudy part. In general, ECHAM4 simulates the location and seasonal shift of the high LWCF over the tropics reasonably well. In January, ECHAM4 does not capture the structure of high LWCF associated with the ITCZ over the eastern equatorial Pacific and the Atlantic as in ERBE. Though high clouds are predicted over those regions, they are possibly optically too thin. ECHAM4 also

\section{ECHAM4 Total Cloud Cover}
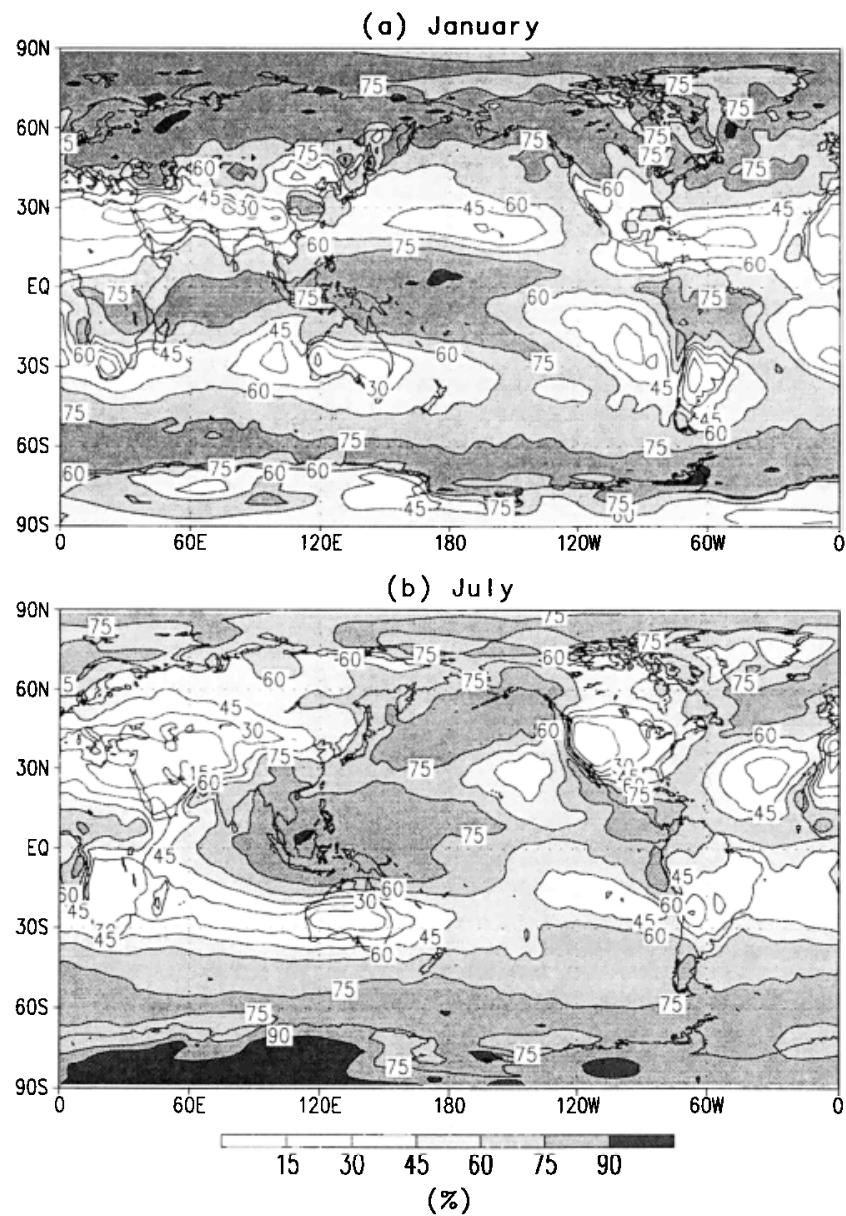

Figure 5. Geographic distribution of total cloud cover: (a) January ECHAM4, (b) July ECHAM4, (c) January International Cloud Climatology Project (ISCCP), and (d) July ISCCP.
Total Cloud Cover

(c) ISCCP January (84-90)

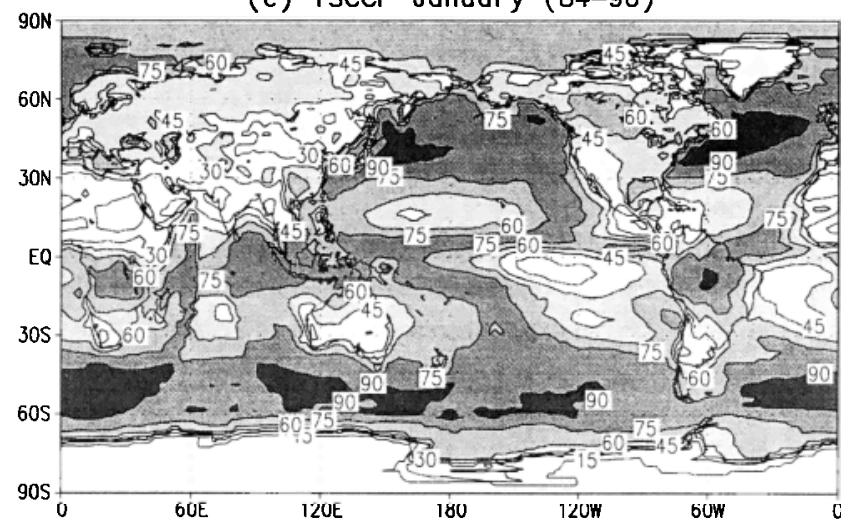

(d) ISCCP July (83-90)

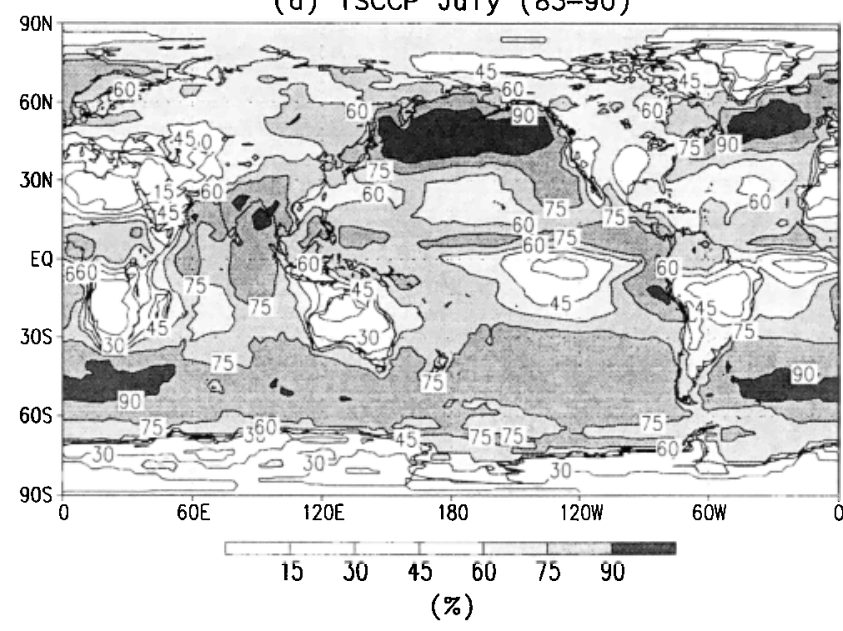

Figure 5. (continued)

underestimates LWCF over Indonesia, and the Congo and Amazon River basins which leads to the generally smaller zonal mean LWCF in the equatorial region (cf. Figure 9a). Similarly, the underestimated LWCF in the North Atlantic and North Pacific storm tracks is causing the maximum zonal mean error at $40^{\circ} \mathrm{N}$. In July, ECHAM4 underestimates the LWCF over the Asian monsoon region and central Africa and overestimates the LWCF over parts of the tropical western Pacific and Indian Ocean and also in the western half of the northern hemisphere ocean basins. The Pacific ITCZ is interrupted in the eastern part by a zone of low LWCF extending from the western United States into the South Pacific. Although both cloud cover and cloud water path indicate a slight interruption of the ITCZ in the eastern equatorial Pacific (cf. Figures 5b and $6 \mathrm{~b}$, respectively), the extremely low LWCF of less than 15 $\mathrm{W} / \mathrm{m}^{2}$ points to little upper level cloudiness resulting from excessive drying by overpredicted large-scale subsidence in that region [Chen et al., 1995].

The zonally averaged January and July SWCF for ERBE and ECHAM4 is shown in Figures 11a and 11b. As to be expected from the respective distributions of planetary albedo (cf. Figure 3), the overestimate of SWCF in the tropics and underestimate of SWCF in the midlatitude summer hemisphere is clearly illustrated in these zonal mean plots with a magnitude of up to $20 \mathrm{~W} / \mathrm{m}^{2}$ in the respective summer hemisphere. 
ECHAM4 Vertical Integrated Cloud Water Path

(a) January

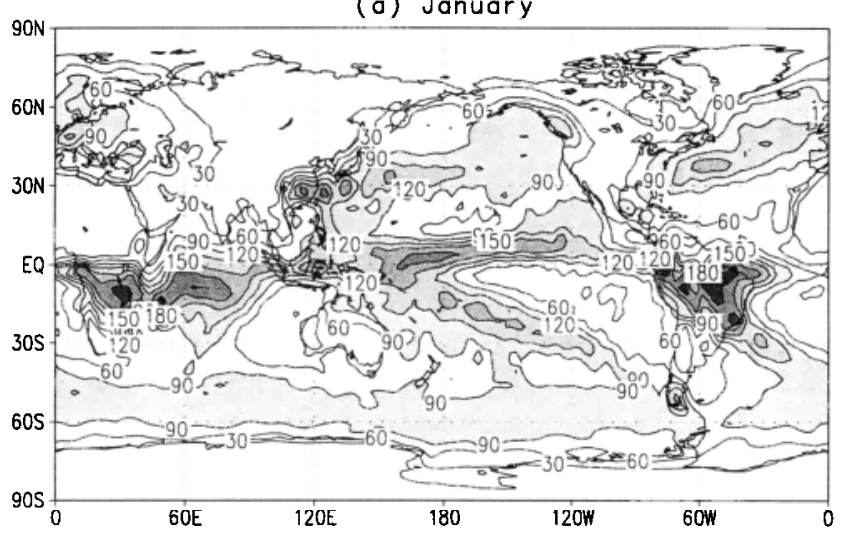

(b) July

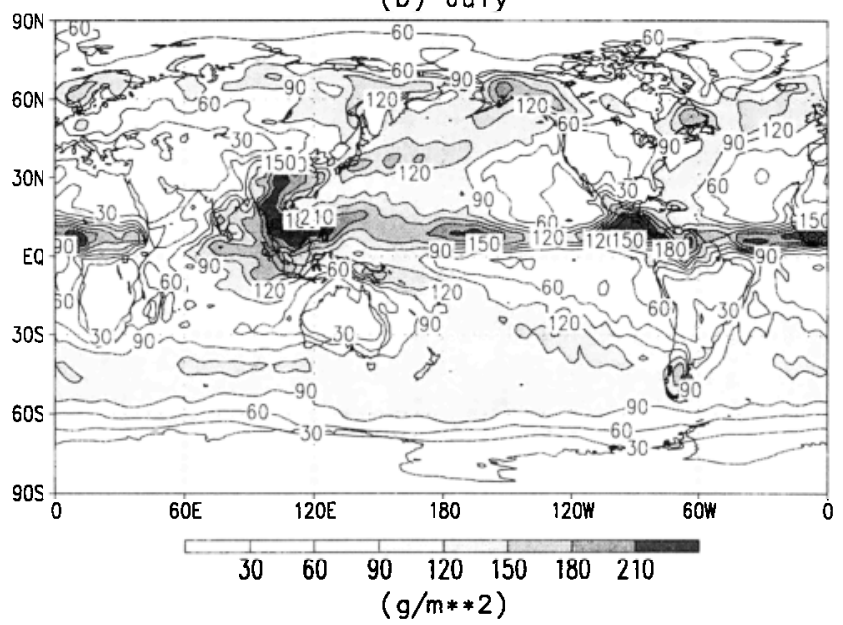

Figure 6. Geographic distribution of total cloud water path simulated by ECHAM4 in (a) January and (b) July.

The geographical distributions of the shortwave cloud radiative forcing from the ERBE observation and ECHAM4 simulation for January and July are shown in Figures 12a-12d. The pattern of large SWCF associated with the ITCZ, SPCZ, and the convection centers over equatorial Africa and CentralSouth America as well as the large SWCF over the summer hemisphere oceanic regions are captured by the model. However, there are generally overestimates $\left(>30 \mathrm{~W} / \mathrm{m}^{2}\right)$ of the SWCF over the tropics and underestimate of SWCF in similar magnitude over the summer hemisphere midlatitude oceans. Over the tropical oceans, regions with very large SWCF $(>100$ $\mathrm{W} / \mathrm{m}^{2}$ ) are more widespread in the model simulation than in the observation, and these regions are characterized by large cloud amount ( $>70 \%$, cf. Figures $5 \mathrm{a}$ and $5 \mathrm{~b}$ ) and large total cloud water path $\left(>150 \mathrm{~g} / \mathrm{m}^{2}\right.$; cf. Figures $6 \mathrm{a}$ and $\left.6 \mathrm{~b}\right)$. A comparison between the simulated and observed cloud amount (cf. Figures 5a-5d) shows that the simulated cloud amount is not excessively high in the tropics. If we exclude, furthermore, a substantial overestimation of the simulated cloud water path, the most likely cause of the SWCF bias is the neglect of cloud water inhomogeneities in the unresolved scales. According to investigations of Davis et al. [1990] and Calahan et al. [1994], the albedo of an optically thick but nonhomogeneous cloud is lower than that of a homogeneous cloud with the same cloud water content, even in the case of an unbroken marine stratocumulus cloud deck. From the modeling perspective, be- cause of the nonlinearity of the radiative transfer computations the grid-averaged radiative flux is not a unique function of the cloud fraction and grid-averaged cloud water path but highly dependent on the sub-grid-scale cloud water distribution [Harshvardhan and Randall, 1985; Stephens and Greenwald, 1991]. A simple method to largely eliminate the cloud albedo bias is used in the Canadian Climate Center GCM2 [MacFarlane et al., 1992] by defining an "effective cloud water path" in the radiative transfer computation through empirical scaling of the grid-averaged cloud water path.

The underestimate in midlatitude SWCF can partly be explained by the underestimated total cloud amount as compared to that in ISCCP data. Moreover, the observed cloud climatology from Warren et al. [1988] (not shown) suggests a prevalence of low stratus cloud over the midlatitude ocean during the summer season. Although the simulated cloud water content shows a low-level maximum at these latitudes, the cloud cover is distributed more uniformly in the vertical than the surface observations seem to indicate (cf. Figure 7). This characteristic in the simulated cloud distribution could lead to a smaller system albedo since the high clouds tend to have a smaller cloud water content than low clouds (cf. Figure 8) and are therefore less reflective.

\subsection{Seasonal Cycle}

To illustrate the seasonal cycle of the Earth radiation budget, the deviations of the monthly mean zonally averaged radiation field from the respective annual mean value have been
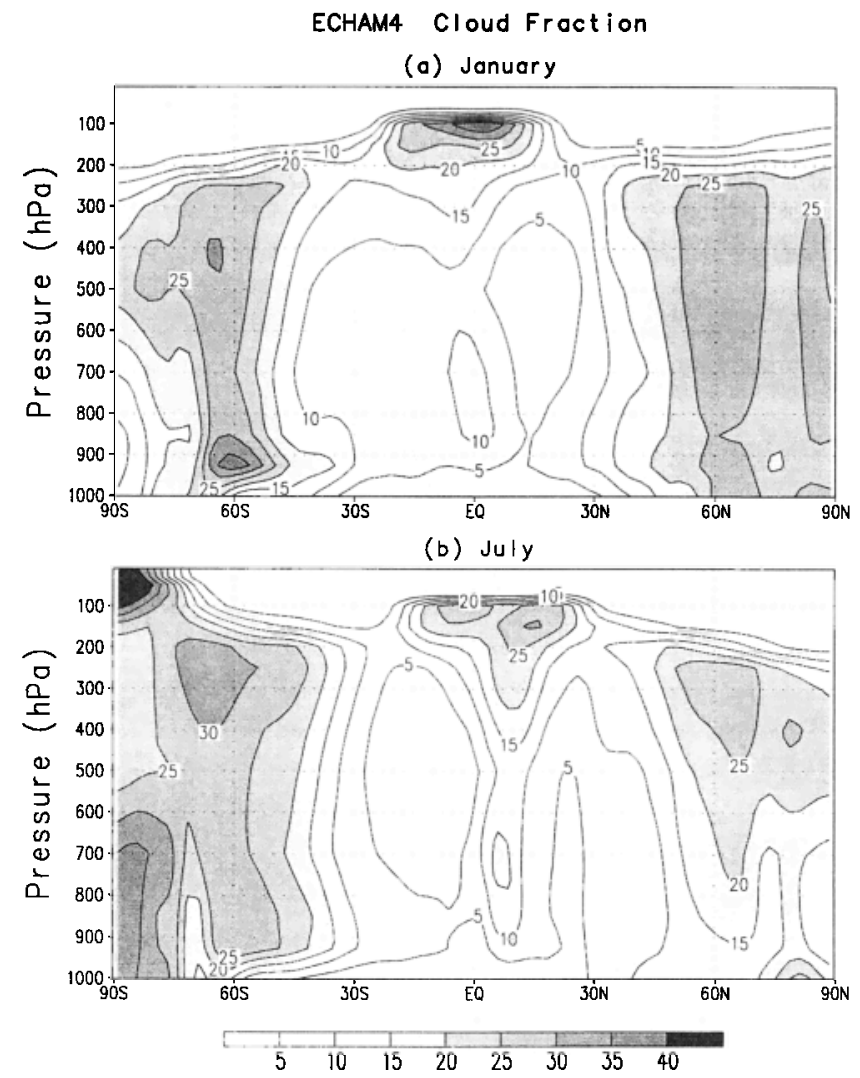

(\%)

Figure 7. Latitude-height cross sections of ECHAM4 ensemble mean zonally averaged cloud fraction for (a) January and (b) July. 
analyzed for ERBE and ECHAM4 data. The amplitude and phase of the seasonal cycle is the main focus here. According to Figures $13 \mathrm{a}$ and $13 \mathrm{~b}$, good agreement between observation and model is found for both amplitude and phase of the seasonal OLR variation. In the tropics the simulated amplitude of OLR is about $5 \mathrm{~W} / \mathrm{m}^{2}$ smaller than ERBE data suggest. The seasonal cycle of planetary albedo from ERBE and ECHAM4 is shown in Figures 14a and 14b. Contrary to the OLR result, the simulated amplitude of planetary albedo is slightly too large in the tropics and in midlatitudes as well. Large differences are particularly evident at high latitudes. However, the limitation of the ERBE observations over these regions have been noted already. Figures $15 \mathrm{a}$ and $15 \mathrm{~b}$ show the seasonal amplitude and phase of LWCF in ERBE and ECHAM4 between $60^{\circ} \mathrm{N}$ and $60^{\circ} \mathrm{S}$. As to be expected from the respective OLR distribution (cf. Figure 13), the phase of the seasonal LWCF variation is well captured by the model, but the amplitude in the tropics is underestimated by $5-10 \mathrm{~W} / \mathrm{m}^{2}$. The sign of the seasonal change with respect to the annual mean value in clear-sky OLR (not shown) is the same as that of OLR. The smaller amplitude of the clear-sky part is due to the smaller effect of seasonal moisture changes as compared to that from seasonal cloud changes. Next we investigate the seasonal variation in SWCF. Since the large seasonal variability of solar irradiance contains no information concerning the cloud effect in different months, we will show the seasonal change in the shortwave cloud radiative forcing resulting from a seasonal change of cloud albedo alone, as referred by Cess $\mathrm{et}$ al. [1992]:

$$
\Delta \mathrm{SWCF}=\left(\Delta \alpha_{\mathrm{clr}}-\Delta \alpha_{\mathrm{lot}}\right) S
$$
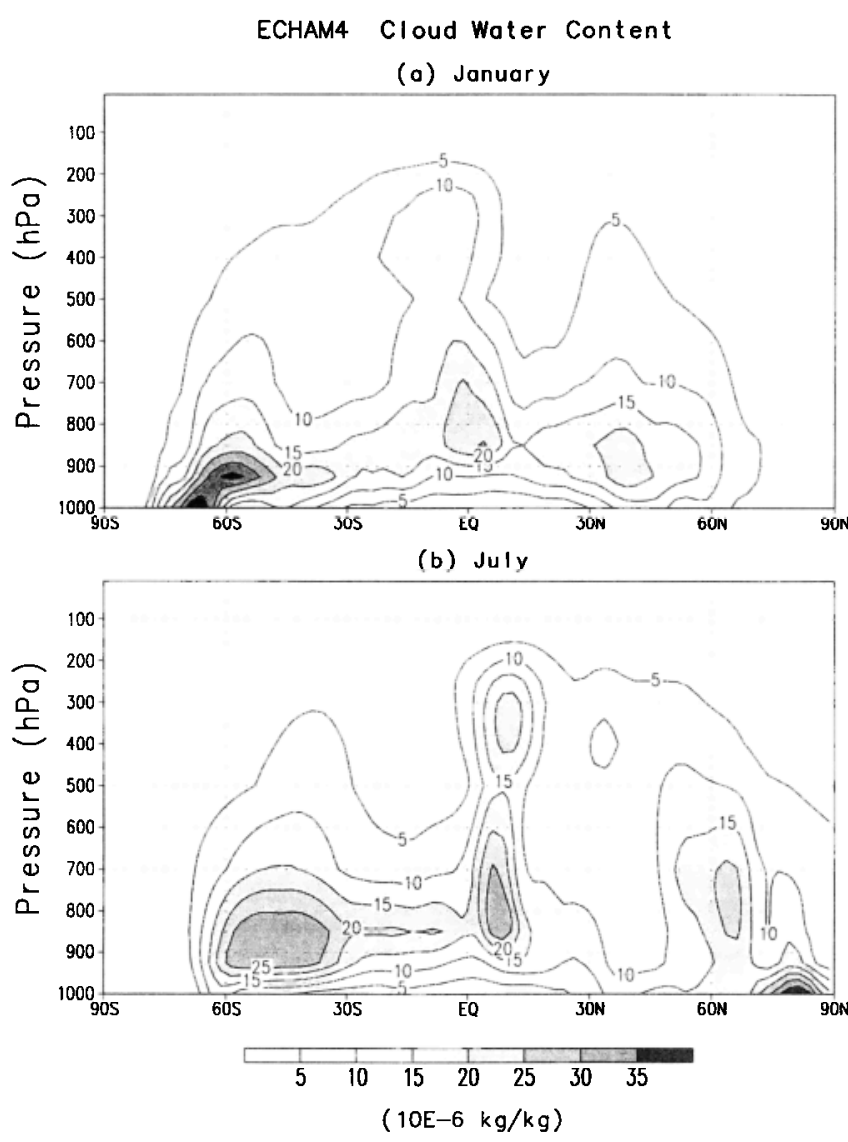

Figure 8. As in Figure 7 except for cloud water content.

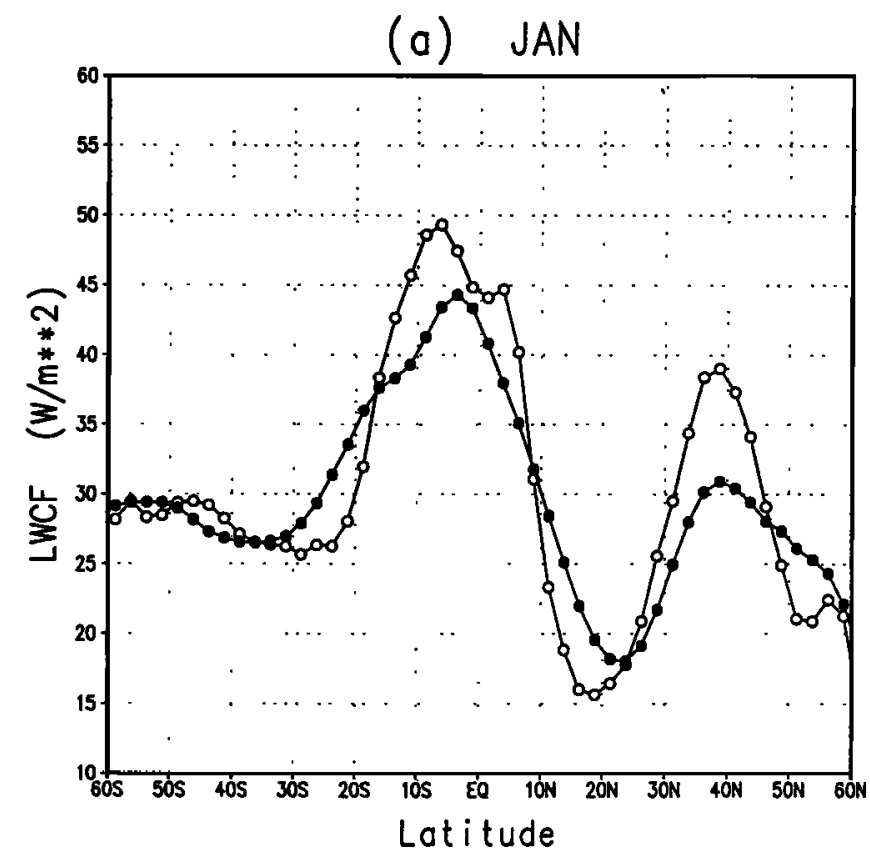

(b) JUL

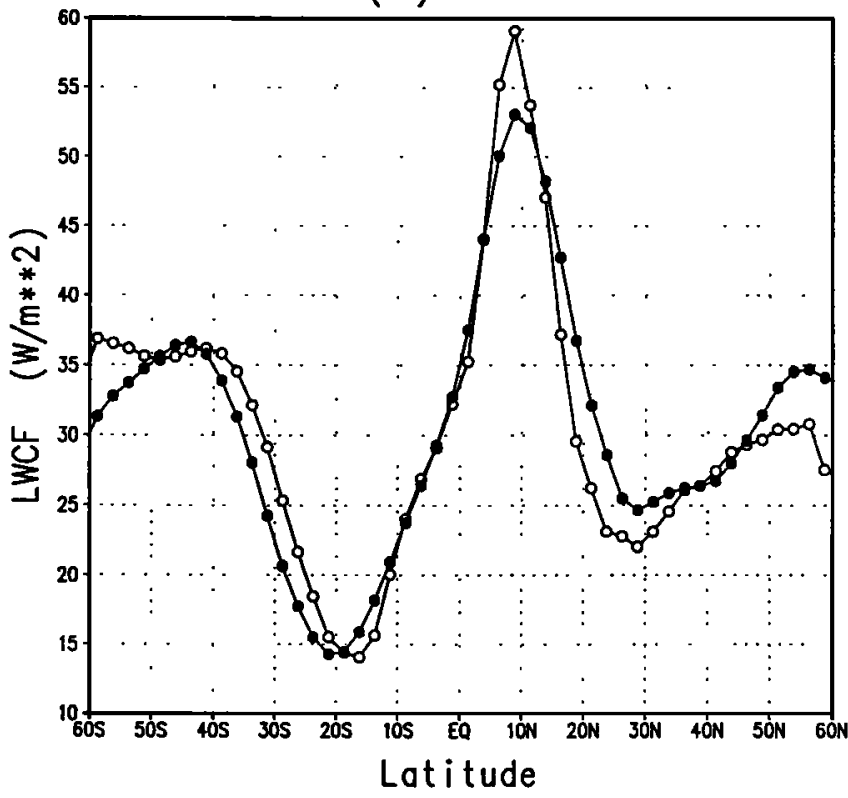

Figure 9. Ensemble mean of zonally averaged longwave cloud radiative forcing from ERBE (open circles) and ECHAM4 (solid circles) for (a) January and (b) July.

$\Delta$ denotes the seasonal perturbation of a given quantity about its annual mean value. $S, \alpha_{\text {tot }}$, and $\alpha_{\mathrm{clr}}$ denote the solar irradiance, albedo, and clear-sky albedo, respectively. The seasonal variation of $\triangle$ SWCF is shown in Figures $16 \mathrm{a}$ and $16 \mathrm{~b}$. The month-latitude distribution of $\triangle \mathrm{SWCF}$ is reasonably well simulated by ECHAM4; however, the amplitude is too large in the tropics (cf. Figure 14). In the northern hemisphere midlatitudes the simulated $\triangle$ SWCF amplitude is smaller than observed, while the opposite is found in the southern hemisphere. The opposite signs of $\triangle \mathrm{LWCF}$ and $\triangle \mathrm{SWCF}$ clearly show the major influence from the seasonal cloud amount changes, since an increase in cloud amount will simultaneously increase the 
LWCF JAN

(a) ERBE

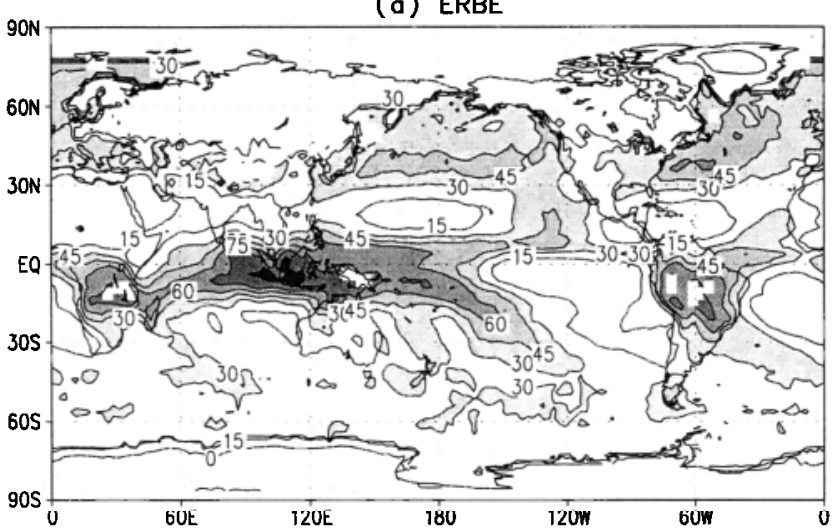

(b) ECHAM4

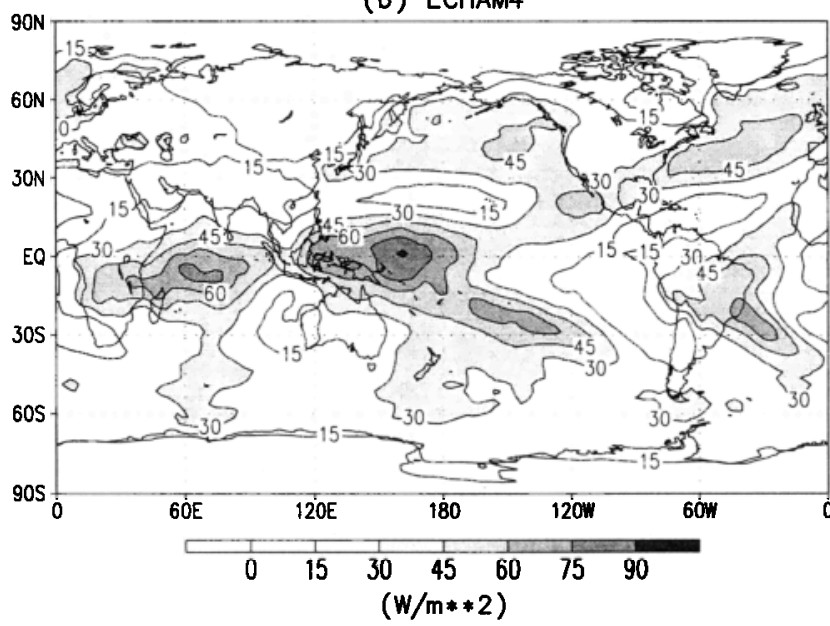

Figure 10. Geographic distribution of the ensemble mean longwave cloud radiative forcing for (a) January ERBE, (b) January ECHAM4, (c) July ERBE, and (d) July ECHAM4.

LWCF heating and SWCF cooling [Cess et al., 1992]. These features are also reproduced by the model.

\subsection{Regional Analyses}

To investigate further the major deficiencies in the model simulation, monthly mean values of longwave and shortwave radiation fields at selected grid points are correlated to diagnose the possible source of error. This technique for regional comparison and understanding of radiative characteristics has been used also in other studies [Kiehl and Ramanathan, 1990; Ramanathan and Collins, 1991; Kiehl et al., 1994]. We select two regions where the model simulation reveals relatively large biases in the previous geographical comparison. The first region is the tropical Pacific and Indian Ocean $\left(20^{\circ} \mathrm{S}-20^{\circ} \mathrm{N}\right.$, $50^{\circ} \mathrm{E}-90^{\circ} \mathrm{W}$ ). The second region is over the Southern Ocean $\left(40^{\circ} \mathrm{S}-55^{\circ} \mathrm{S}\right)$. Since we have shown earlier that the difference of model and observation in OLR and planetary albedo are mainly due to the cloudy part of sky, we only discuss the cloud radiative forcing in these regional analyses.

3.4.1. Tropical Pacific and Indian Oceans. Scatterplots of January LWCF versus SWCF over this region from ERBE and ECHAM4 are shown in Figures $17 \mathrm{a}$ and $17 \mathrm{~b}$, respectively. While the range of LWCF is well captured by the model, the tropical SWCF bias mentioned earlier is clearly evident in the scatterplot. While ERBE data suggest a near cancelation of both components for much of the regime, the modeled SWCF is typically $20 \mathrm{~W} / \mathrm{m}^{2}$ larger than LWCF. Scatterplots of SWCF versus total cloud cover for both observation (Figure 18a) and simulation (Figure 18b) confirm the earlier conclusion that the SWCF bias is not caused by a too large cloud cover. In fact, the observed nonlinear shape of the distribution as well as the range of total cloud amount are very well reproduced by the model. Moreover, since also the simulated cloud water path is within the range of current estimates (not shown), the most likely candidate for the SWCF bias is the neglect of sub-gridscale cloud water variability in the radiative transfer code (cf. section 3.2).

3.4.2. Southern Ocean. The same scatterplots discussed above for the tropics are shown for the Southern Ocean in January (Figures 19a and 19b and Figures 20a and 20b, respectively). According to ERBE the LWCF is scattered around 30 $\mathrm{W} / \mathrm{m}^{2}$ for a wide range of SWCF values. This means that the SWCF variability is not due to variations of cloud cover, cloud height, or high-cloud optical depth, since all that would affect the LWCF as well, but rather by variations of cloud water content and hence optical depth of optically thick low clouds. In the model simulation (Figure 19b) the clustering of LWCF around $30 \mathrm{~W} / \mathrm{m}^{2}$ is reproduced for high SWCF beyond about $100 \mathrm{~W} / \mathrm{m}^{2}$, but the range of simulated SWCF is clearly underestimated. Moreover, different from the observations, there is

LWCF JUL

(c) ERBE

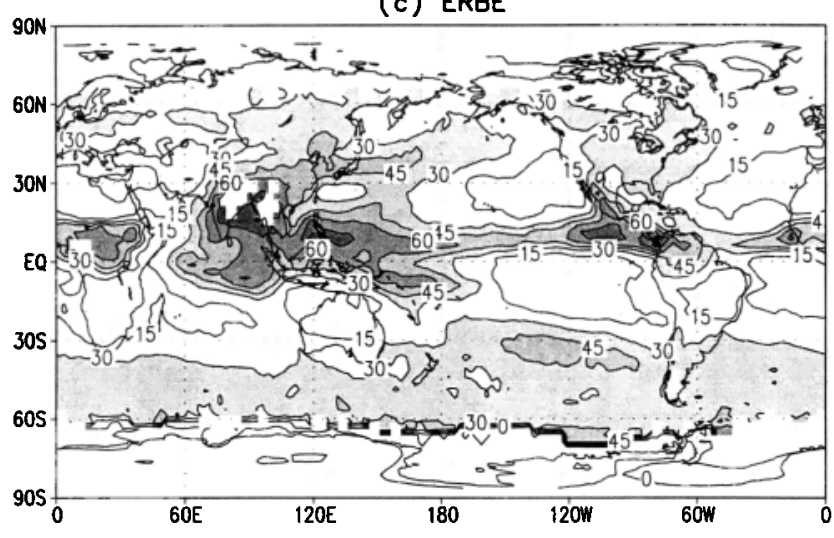

(d) ECHAM4

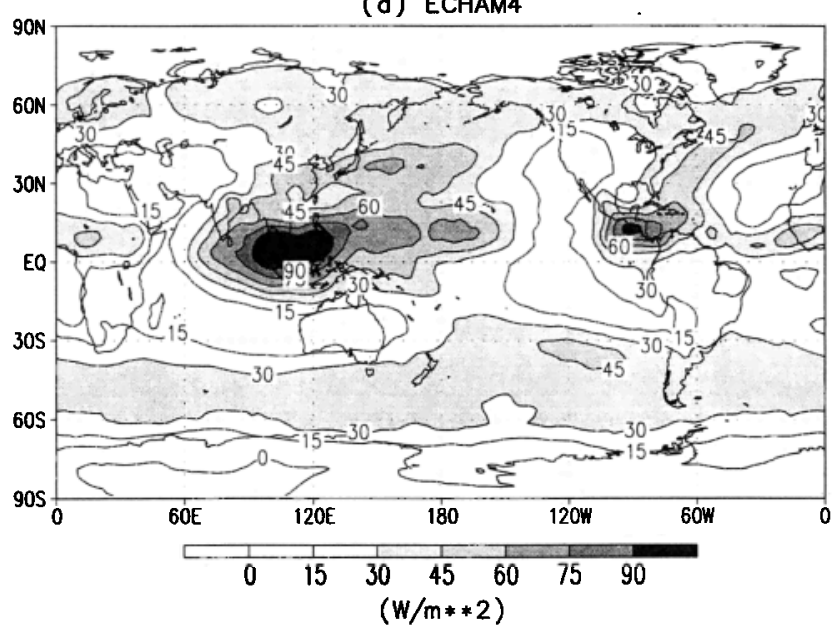

Figure 10. (continued) 
a relatively high correlation between both components for smaller SWCF values.

According to Figure 20 which shows the observed and simulated scatterplots of SWCF versus total cloud cover, the most likely reason for the low SWCF bias in the model is underestimated cloud cover. While the spatial variability of ISCCP total cloud cover in this region is relatively small with values mostly between 80 and $100 \%$, the simulated cloud cover is generally in the range between 50 and $80 \%$, and there is a high correlation between SWCF and total cloud cover. The same problem occurs over the North Pacific and North Atlantic where the simulated low-level cloudiness is generally too small in summer.
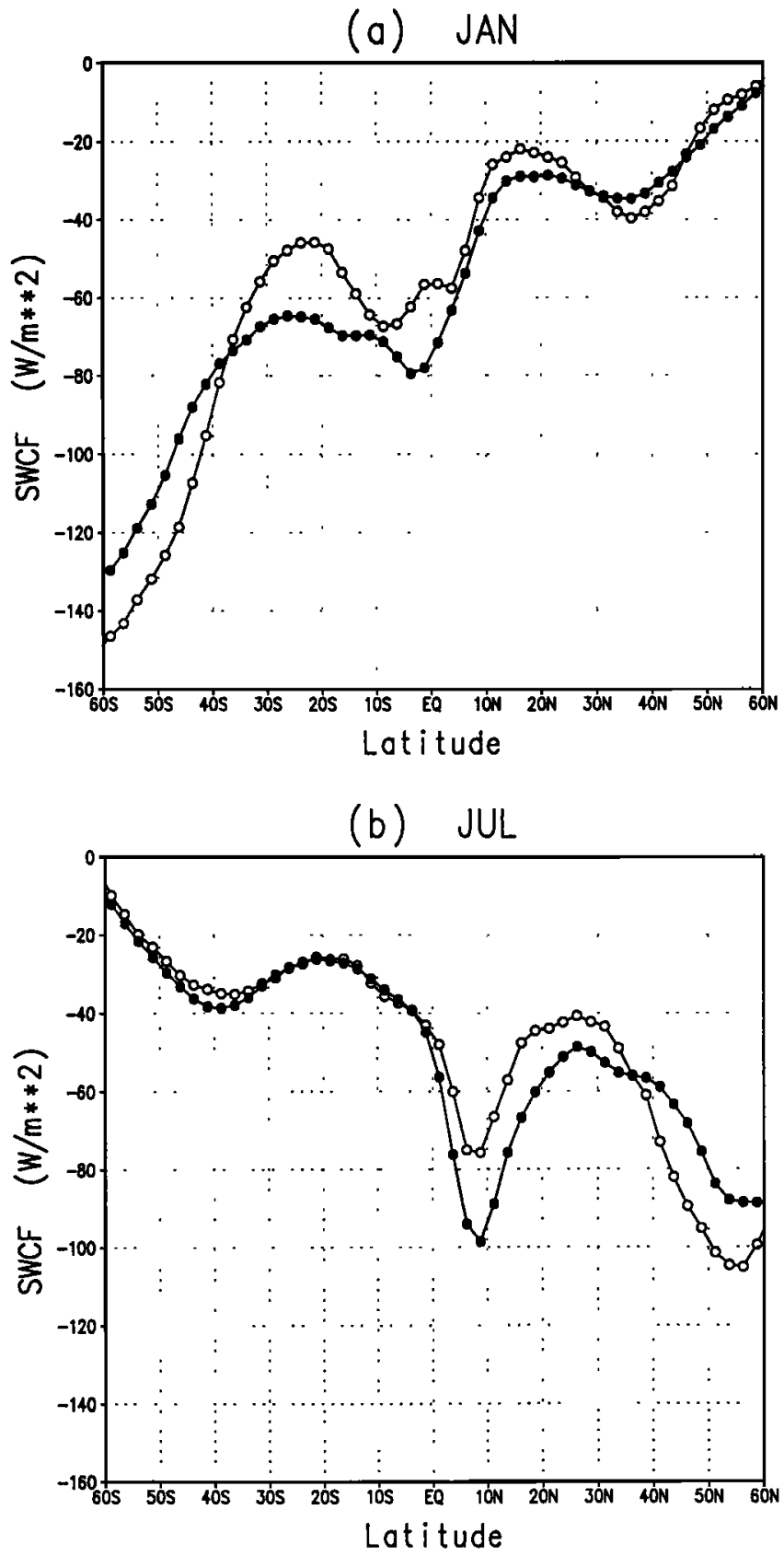

Figure 11. Ensemble mean of zonally averaged shortwave cloud radiative forcing from ERBE (open circles) and ECHAM4 (solid circles) for (a) January and (b) July.
SWCF JAN

(a) ERBE

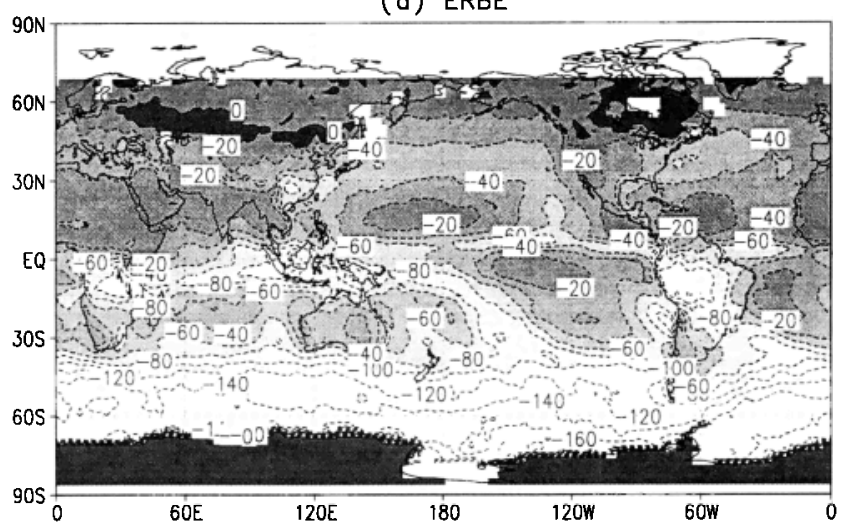

(b) ECHAM4

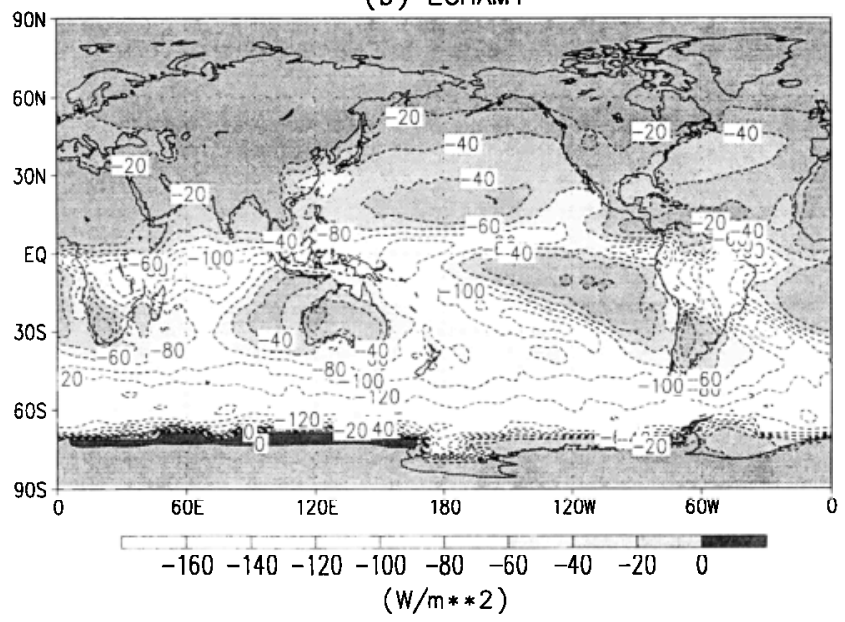

Figure 12. Geographic distribution of the ensemble mean shortwave cloud radiative forcing for (a) January ERBE, (b) January ECHAM4, (c) July ERBE, and (d) July ECHAM4.

\subsection{Tropical Interannual Variability in Cloud Radiative Forcing}

According to observations [e.g., Rasmussen, 1991] the interannual variability of the tropical circulation is closely connected with interannual SST variations related to the El Niño/ Southern Oscillation (ENSO) cycle. The atmospheric variability caused by tropical SST anomalies is also reasonably well simulated by GCMs forced with observed SSTs [Lau, 1985; Barnett et al., 1991; Bengtsson et al., 1994]. The large-scale circulation changes associated with ENSO events are expected to alter the cloud distribution and radiation fields which contribute to maintain the anomalous circulation through a positive feedback loop [Barnett et al., 1991; Sherwood et al., 1994; Lohmann and Roeckner, 1995]. Hence in addition to the validation of the mean radiation fields and their seasonal variations, the evaluation of the model's capability in reproducing cloud-climate interactions during the occurrence of a specific phenomenon such as ENSO is equally important and can be achieved by examining the corresponding cloud radiative forcing.

The skill of the previous model version (ECHAM3) in simulating the observed cloud radiative response to the interannual SST variations in the tropical Pacific has been discussed by Lohmann and Roeckner [1995]. Using ERBE data, they 


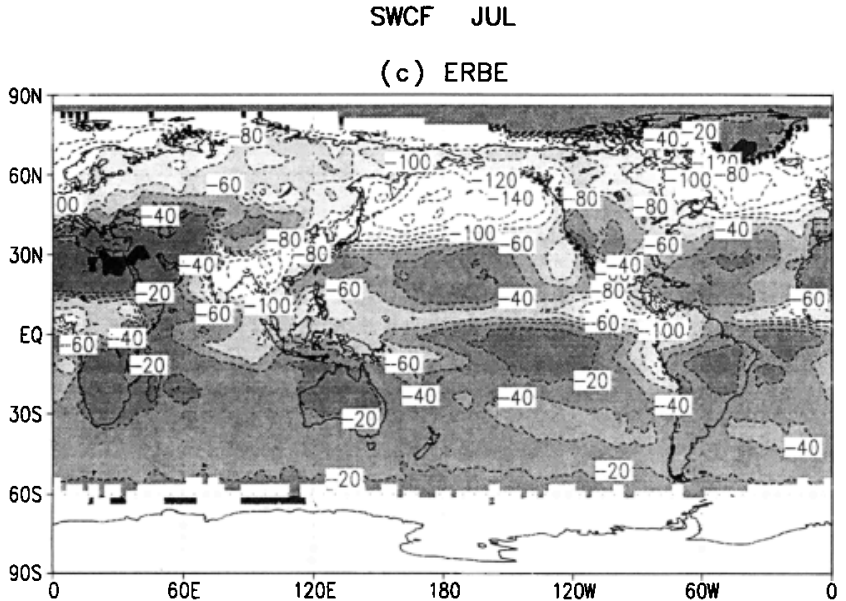

(d) ECHAM4

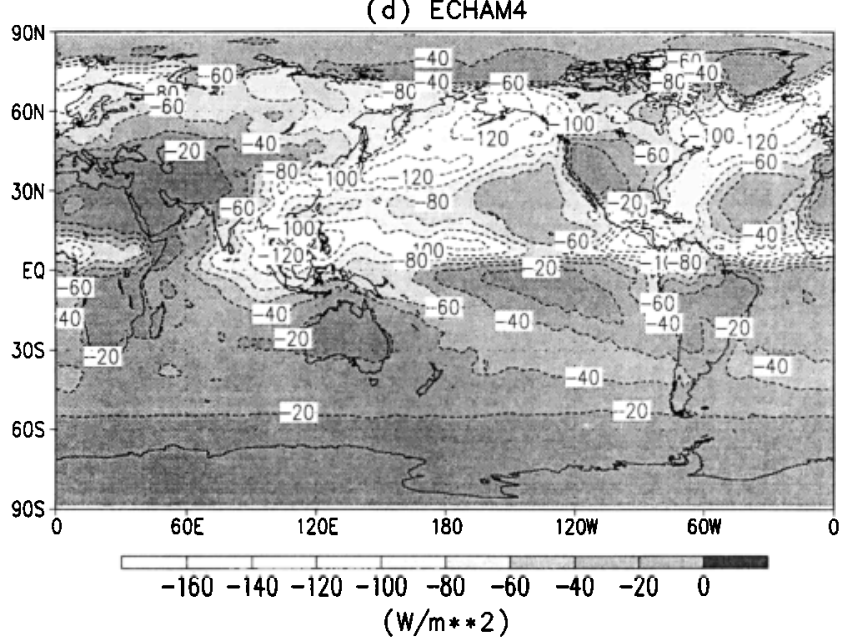

Figure 12. (continued)

show that both phase and amplitude of the LWCF anomalies are captured by ECHAM3. The simulated SWCF anomalies, however, are systematically larger than those observed. In this section the same analysis is applied to the new model (ECHAM4). High-frequency noise is eliminated from all data by a 5 -month running mean operator. The temporal evolution of SST anomalies $\left(5^{\circ} \mathrm{N}-5^{\circ} \mathrm{S}\right)$ along the equator, calculated from the AMIP data set for the same time period for which ERBE observations are available, is shown in Figure 21. The pattern is characterized by a sequence of cold ( $\mathrm{La} \mathrm{Nin̄a)} \mathrm{and} \mathrm{warm} \mathrm{(} \mathrm{El}$ Niño) events with largest anomalies of up to $2 \mathrm{~K}$ in the eastern Pacific. During an El Niño year such as 1987 the deep convection and associated cloud fields, normally situated over the western Pacific warm pool and associated with the ascending branch of the Walker circulation, are shifted eastward over the anomalous SST maximum in the central and eastern Pacific [Webster, 1983], roughly $60^{\circ}$ westward of the largest SST anomalies (cf. Figure 21). These changes are reflected in the ERBE data as a positive LWCF anomaly with a peak value of slightly more than $40 \mathrm{~W} / \mathrm{m}^{2}$ around the dateline in 1987 (Figure 22a) and a corresponding negative SWCF anomaly with a peak value of $-50 \mathrm{~W} / \mathrm{m}^{2}$ (Figure 22b). During the La Niña years of 1985 and 1988 the sign of the anomalies is reversed and the amplitudes are somewhat smaller. Figure 23 shows the respective cloud radiative forcing anomalies simulated by the model. While the anomaly patterns of both components are well cap- tured, the LWCF amplitudes tend to be smaller than those observed, and the SWCF amplitudes are slightly larger. However, the deviations are generally within the range of observational errors which is estimated to be about $10 \mathrm{~W} / \mathrm{m}^{2}$ for ERBE data.

Changes in cloud radiative forcing can be caused by changes in cloud amount, cloud vertical structure, and cloud optical properties. We discuss further the possible causes for the observed and simulated SWCF and LWCF anomalies. From the model output, the above cloud-related quantities can be retrieved easily. However, the climatological cloud observations other than total cloud amount are not very reliable and cannot reveal the complete picture in the vertical distribution due to the limitation of the data sampling. In addition, there are spurious changes found in the observed data set [Klein and

\section{Seasonal Variation of OLR}

(a) ERBE

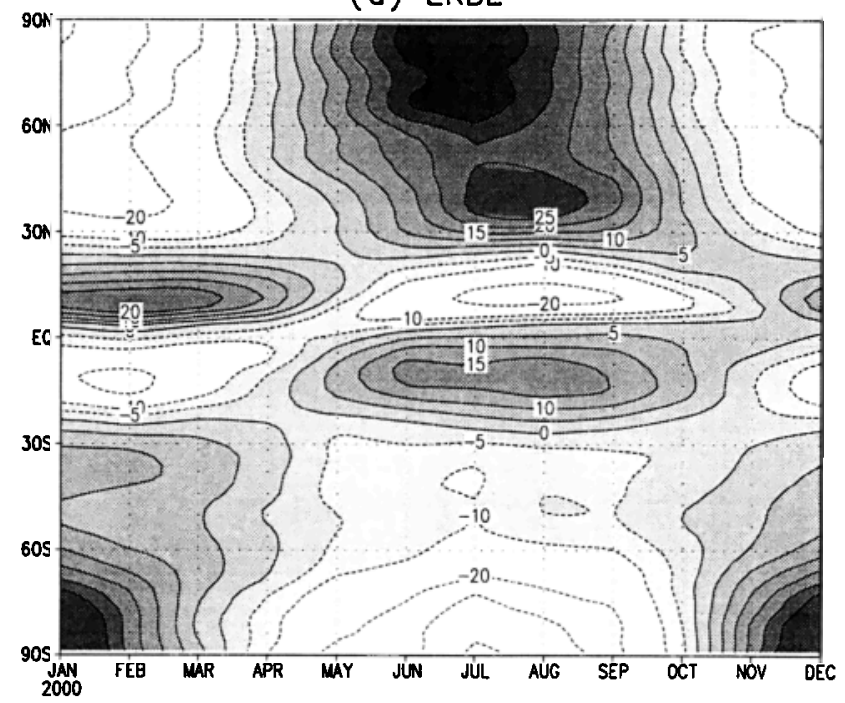

(b) ECHAM4

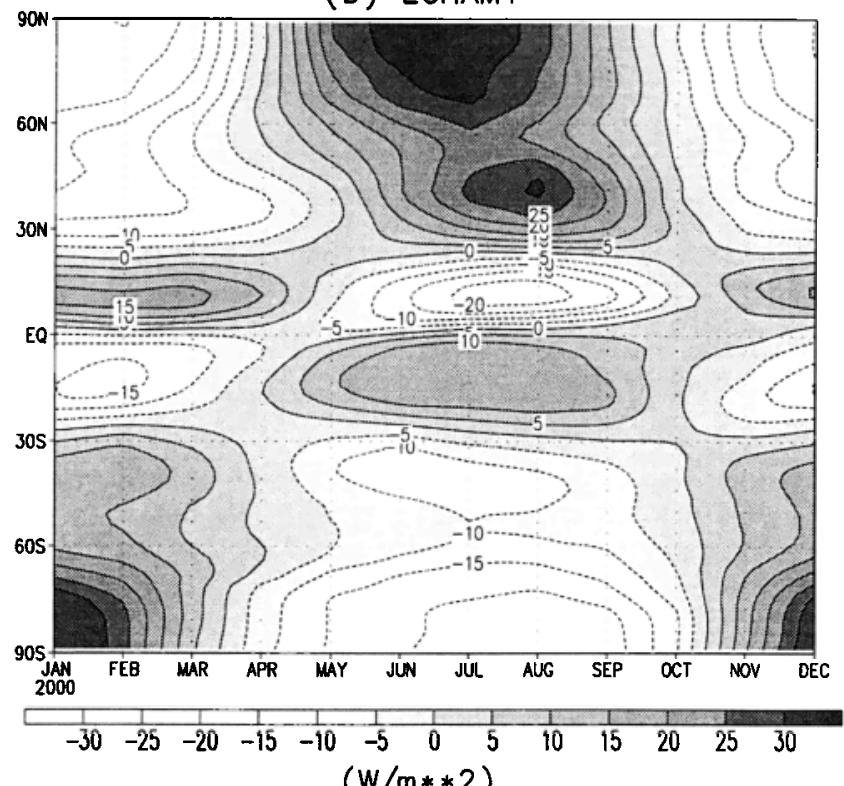

$(w / m * * 2)$

Figure 13. Latitude-month distribution of the seasonal variation in zonally averaged outgoing longwave radiation deviations from the annual mean for (a) ERBE and (b) ECHAM4. 
Hartmann, 1993]. Thus we only show the equatorial total cloud cover anomalies derived from ISCCP data. In the face of these limitations, there are still some interesting findings. Figure 24 shows the equatorial $\left(5^{\circ} \mathrm{N}-5^{\circ} \mathrm{S}\right)$ total cloud fraction anomalies for the same period as derived from the ISCCP data set. A high correlation between the anomalies of ISCCP total cloud cover and ERBE cloud radiative forcing is demonstrated. One can identify the location and time of the peak anomalies during warm and cold events from both analyses. The corresponding simulation is illustrated in Figure 25a. The sign of the anomalies is captured by the model; however, the magnitude of the peak anomalies is much smaller than the ISCCP data suggest. Also, the simulated anomalies are located more eastward than the peak anomalies found in the ISCCP observation. Comparing the temporal and spatial distribution of the equatorial cloud radiative forcing simulated in the model, it is less evident

\section{Seasonal Variation of Planetary Albedo}

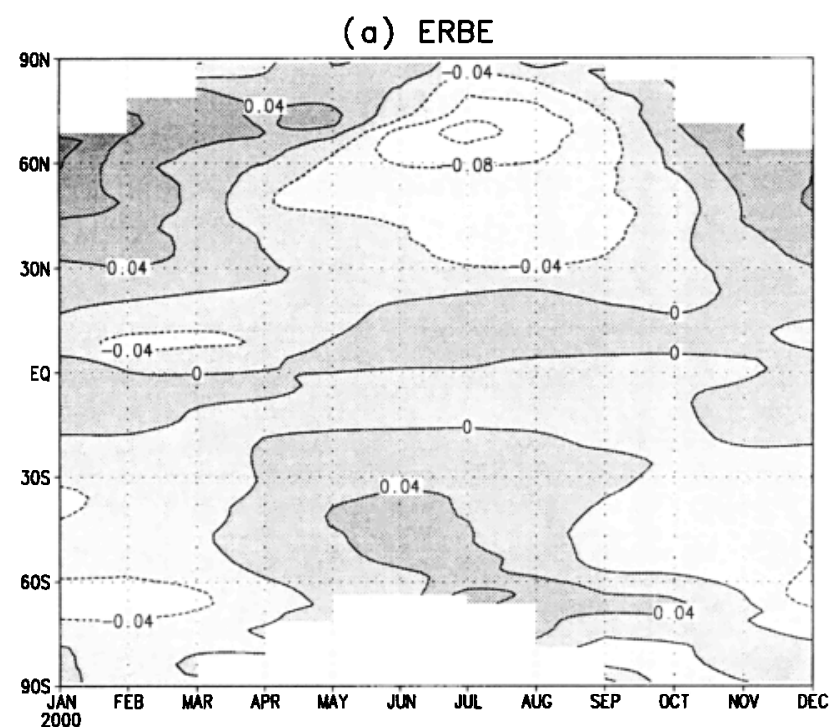

(b) ECHAM4

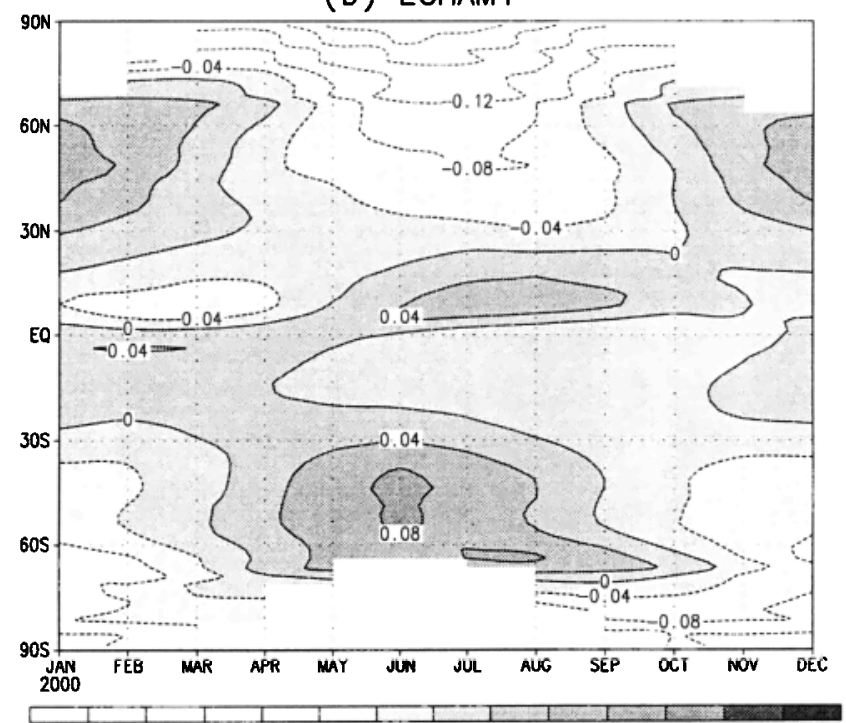

$-0.24-0.2-0.16-0.12-0.08-0.04 \quad 0 \quad 0.04 \quad 0.080 .120 .16 \quad 0.20 .24$

Figure 14. Latitude-month distribution of the seasonal variation in zonally averaged planetary albedo deviations from the annual mean for (a) ERBE and (b) ECHAM4.
Seasonal Variation of LWCF

(a) ERBE

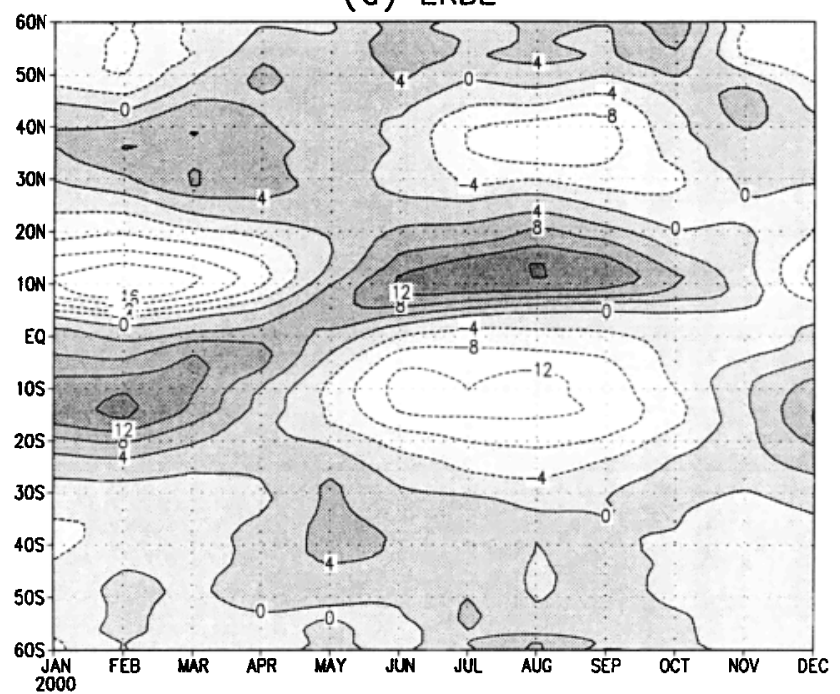

(b) ECHAM4

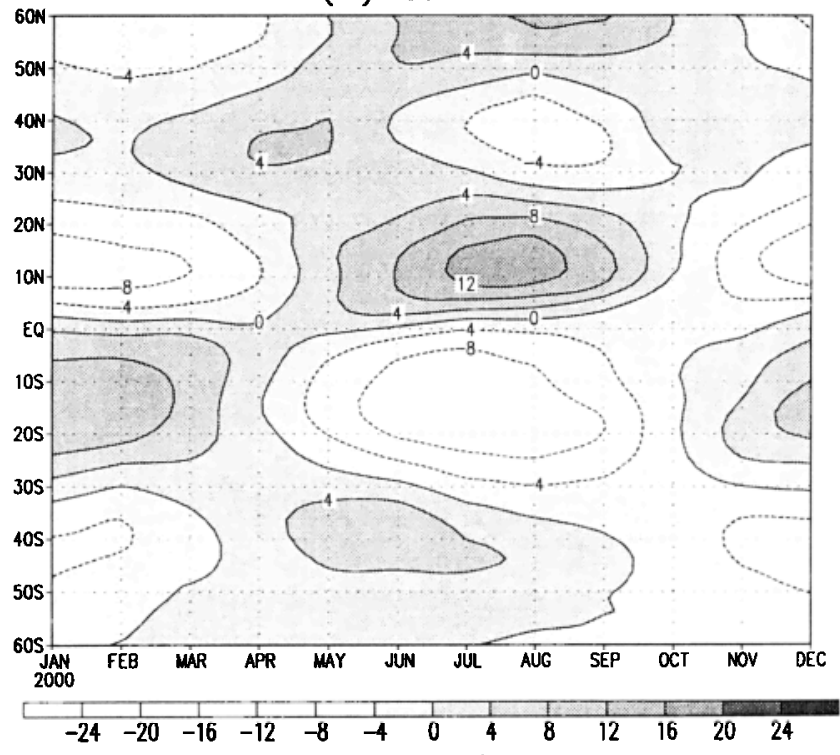

$(W / m * * 2)$

Figure 15. Latitude-month distribution of the seasonal variation in zonally averaged longwave cloud radiative forcing deviations from the annual mean for (a) ERBE and (b) ECHAM4.

that the peak anomalies in cloud radiative forcing are caused by the cloud cover changes. On the other hand, according to Figure 25b, which shows the simulated space-time distribution of the total cloud water path anomalies along the equator, there is a high degree of coherence between the cloud water anomalies and both components of the cloud radiative forcing (Figure 23), especially for SWCF. This high correlation is evident throughout the equatorial domain. The different causes for the tropical cloud radiative forcing anomalies can also be demonstrated from the standard deviation of observed and simulated cloud fields. Using the data from 1984 to 1990 , Figures 26a-26c show the interannual standard deviations of the annual mean total cloud cover from ISCCP and the annual mean total cloud cover and total cloud water path from 


\section{Seasonal Variation of SWCF}

(a) ERBE

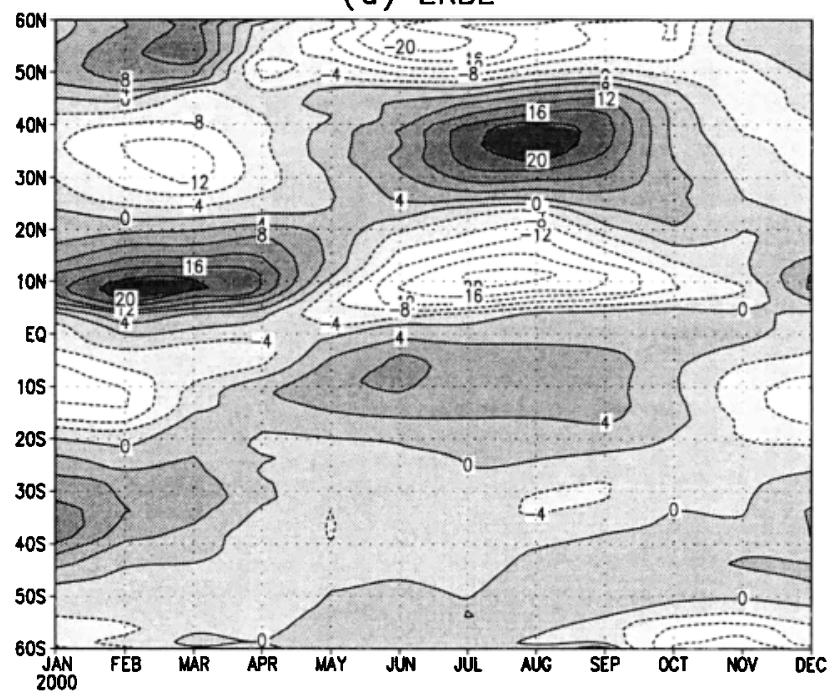

(b) ECHAM4

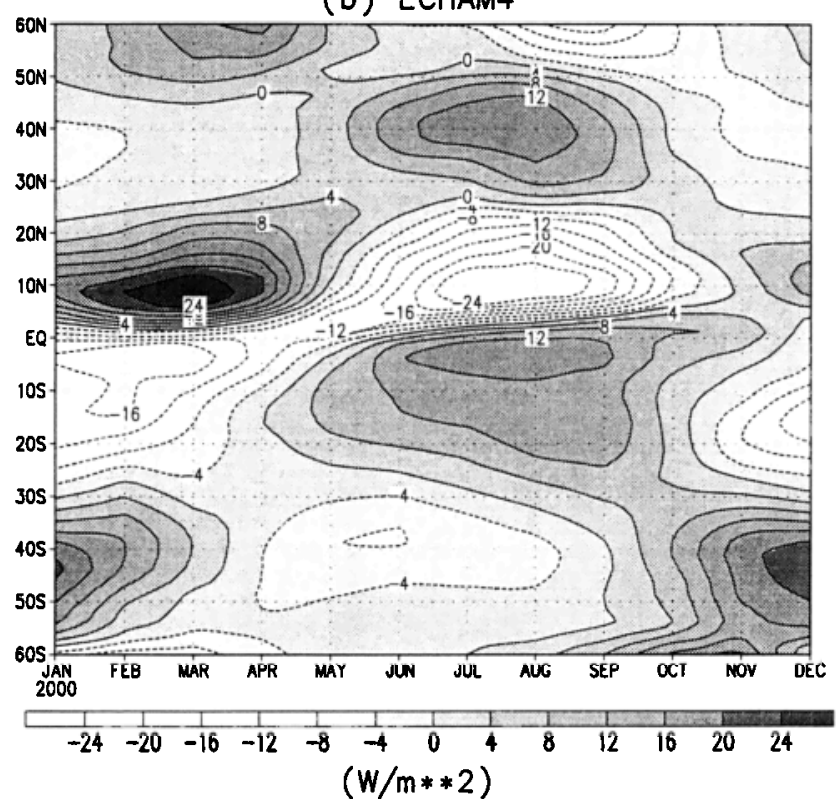

Figure 16. Latitude-month distribution of the seasonal variation in zonally averaged shortwave cloud radiative forcing deviations from the annual mean (as referred by Cess et al. [1992]) for (a) ERBE and (b) ECHAM4.

ECHAM4, respectively. While the maximum interannual variability in observed total cloud cover is located near the dateline at the equator, larger variabilities in the simulated total cloud cover are found near $120^{\circ} \mathrm{E}$ and $150^{\circ} \mathrm{W}$ in the tropics. On the other hand, the maximum standard deviation in the simulated annual mean total cloud water path resides in the equatorial central Pacific, in better correspondence to the pattern of ISCCP total cloud cover variability.

\section{Discussion and Conclusions}

In this study we show that the observed distribution of the Earth radiation budget is largely reproduced by the latest version of the Max Planck Institute for Meteorology general cir- culation model (ECHAM4). Good agreement with ERBE data is found (1) for the zonally averaged clear-sky radiation (shortwave and longwave) and total OLR, (2) for the seasonal cycle of zonally averaged OLR, planetary albedo, and cloud radiative forcing, and (3) for the cloud radiative response to interannual sea surface temperature variations in the tropics.

On a regional scale the errors in the longwave cloud radiative forcing and thus OLR are partly related to deficiencies of the simulated circulation. Because of the excessively strong Walker circulation [Chen et al., 1995], the ITCZ is not as

(a) ERBE January

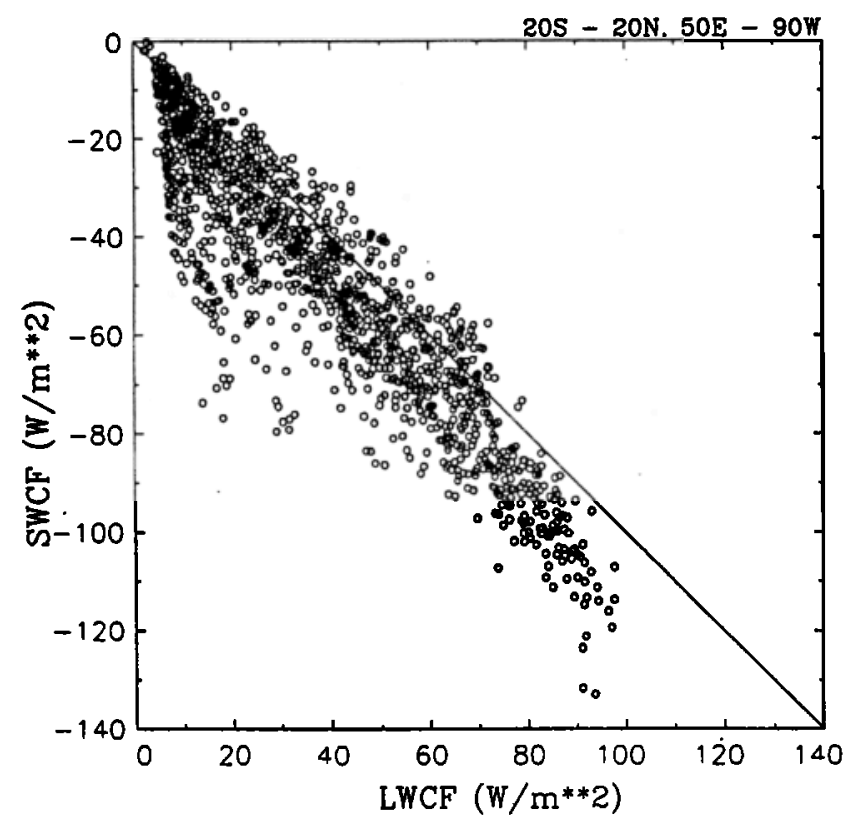

(b) ECHAM4 January

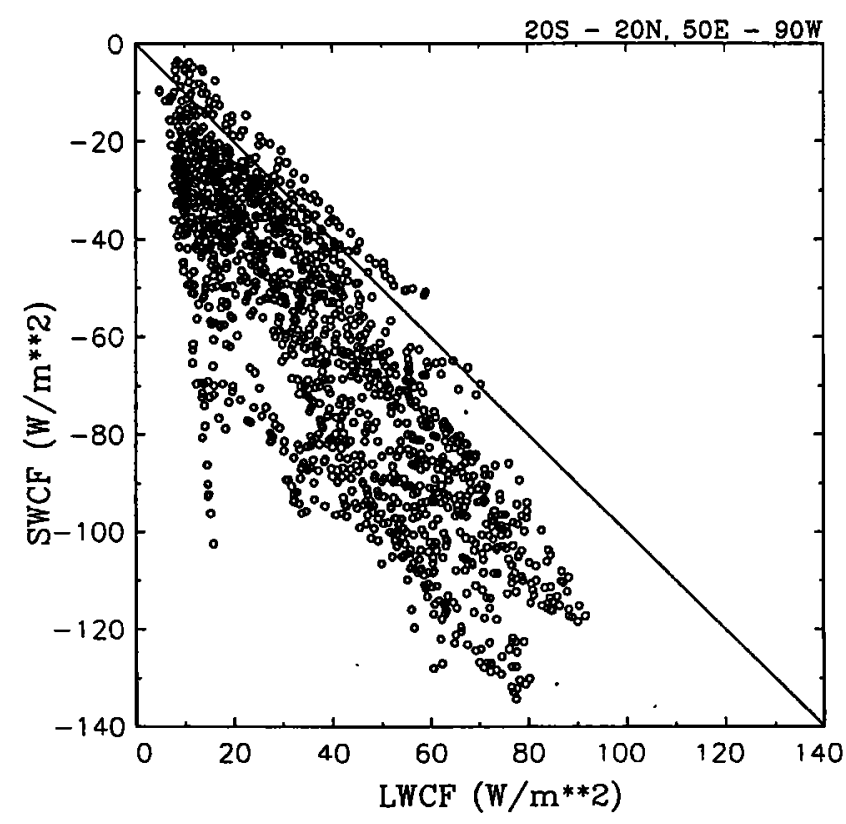

Figure 17. January shortwave cloud radiative forcing versus longwave cloud radiative forcing for the tropical Pacific and Indian Ocean region $\left(20^{\circ} \mathrm{S}-20^{\circ} \mathrm{N}, 50^{\circ} \mathrm{E}-90^{\circ} \mathrm{W}\right)$ from (a) ERBE and (b) ECHAM4. 
coherent as ERBE data indicate, and the band of low OLR associated with deep convection in the tropics is sometimes interrupted by anomalous upper level subsidence as, for example, in the East Pacific, especially during July, and over Central Indonesia during January. Similarly, the overestimation of OLR over India and Southeast Asia in July is primarily caused by a relatively weak monsoonal flow (ER95). Over the tropical continents, on the other hand, insufficient cloud optical depth is the most likely cause for the excess OLR. In fact, additional sensitivity experiments indicate that the persistently low longwave cloud radiative forcing over the tropical continents is

(a) ERBE/ISCCP January

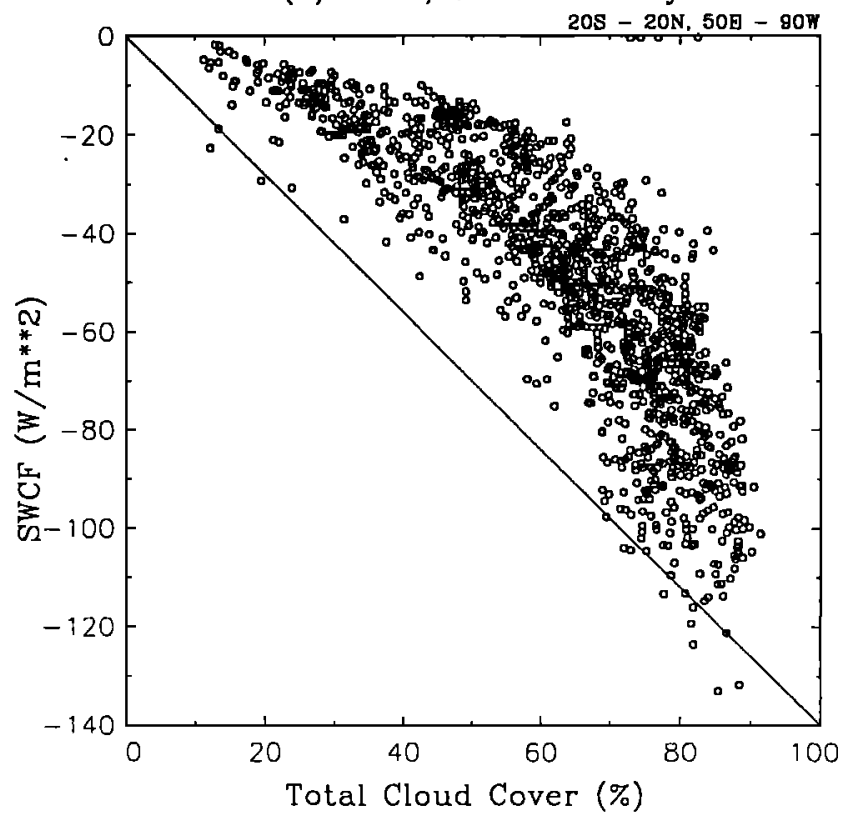

(b) ECHAM4 January

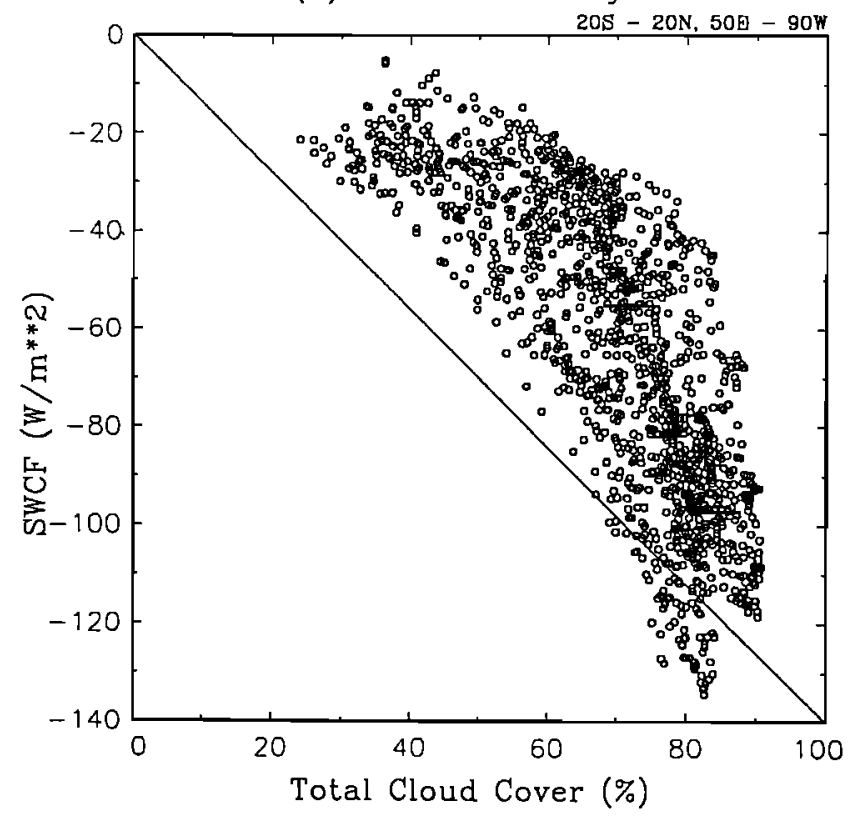

Figure 18. January total cloud cover versus shortwave cloud radiative forcing for the tropical Pacific and Indian Ocean region $\left(20^{\circ} \mathrm{S}-20^{\circ} \mathrm{N}, 50^{\circ} \mathrm{E}-90^{\circ} \mathrm{W}\right.$ ) from (a) observations (ERBE and ISCCP) and (b) ECHAM4. (a) ERBE January

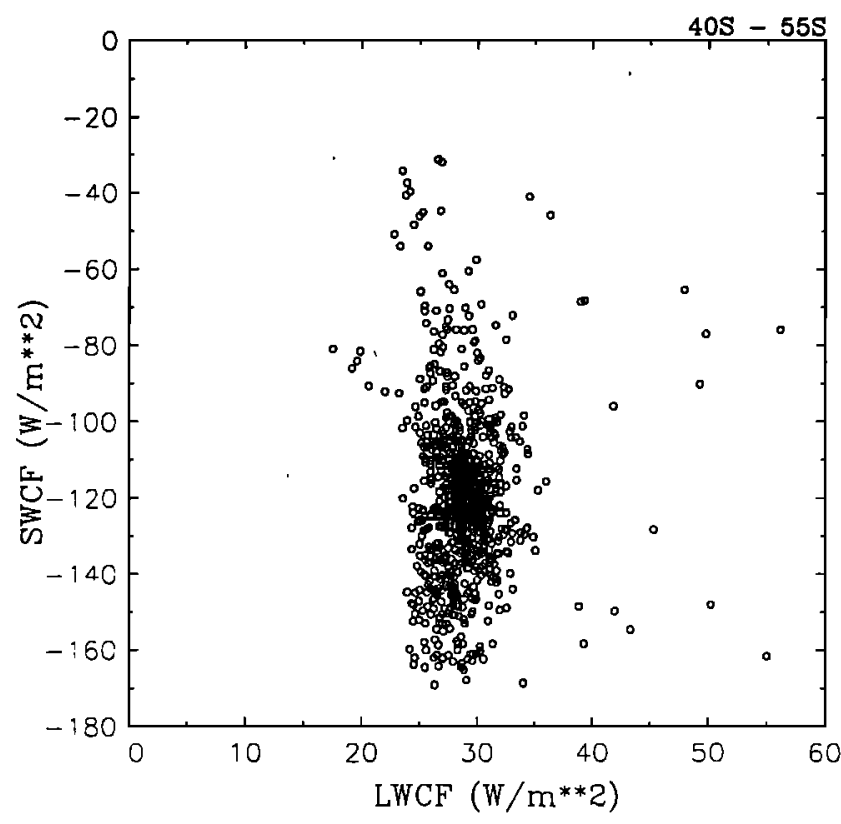

(b) ECHAM4 January

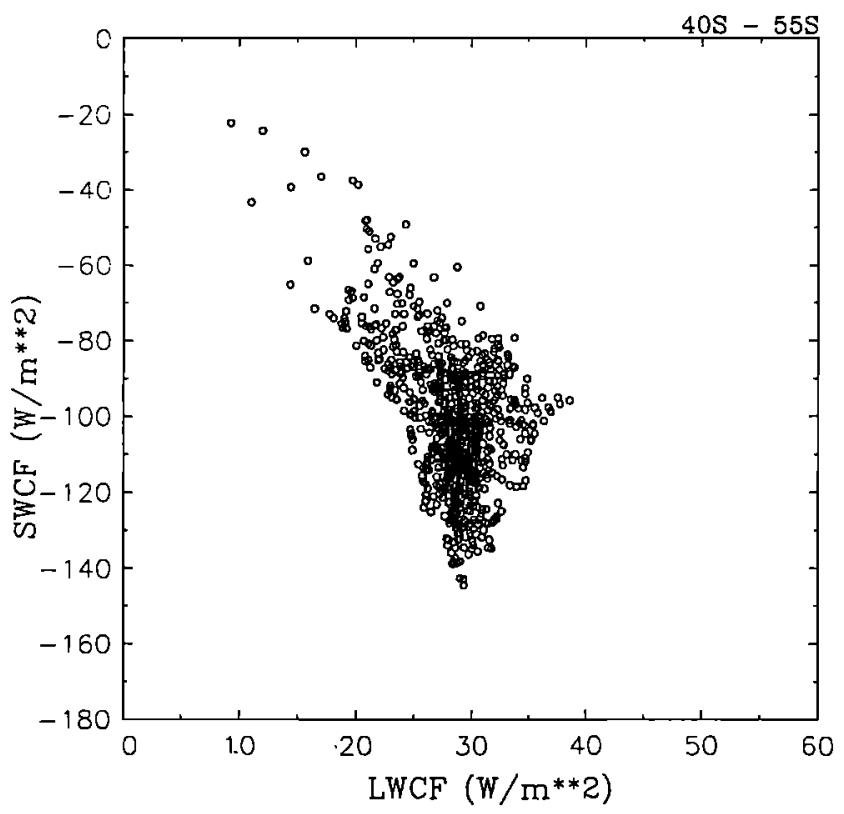

Figure 19. January shortwave cloud radiative forcing versus longwave cloud radiative forcing for the Southern Ocean region $\left(40^{\circ} \mathrm{S}-55^{\circ} \mathrm{S}\right)$ from (a) ERBE and (b) ECHAM4.

caused by a lack of ice water storage in cirrus anvils due to a relatively high precipitation efficiency coefficient used in the convection scheme [Tiedtke, 1989].

The most serious problem, however, which has already been noted in previous validation studies [e.g., Kiehl et al., 1994] is the bias in shortwave cloud radiative forcing. In the ECHAM4 model, the SWCF is too large throughout the year in convectively active areas over the tropical oceans (ITCZ, SPCZ) but too small over the midlatitude oceans during summer. While the latter problem, according to ISCCP data, is very likely caused by insufficient cloudiness in these regions (presumably 
(a) ERBE/ISCCP January

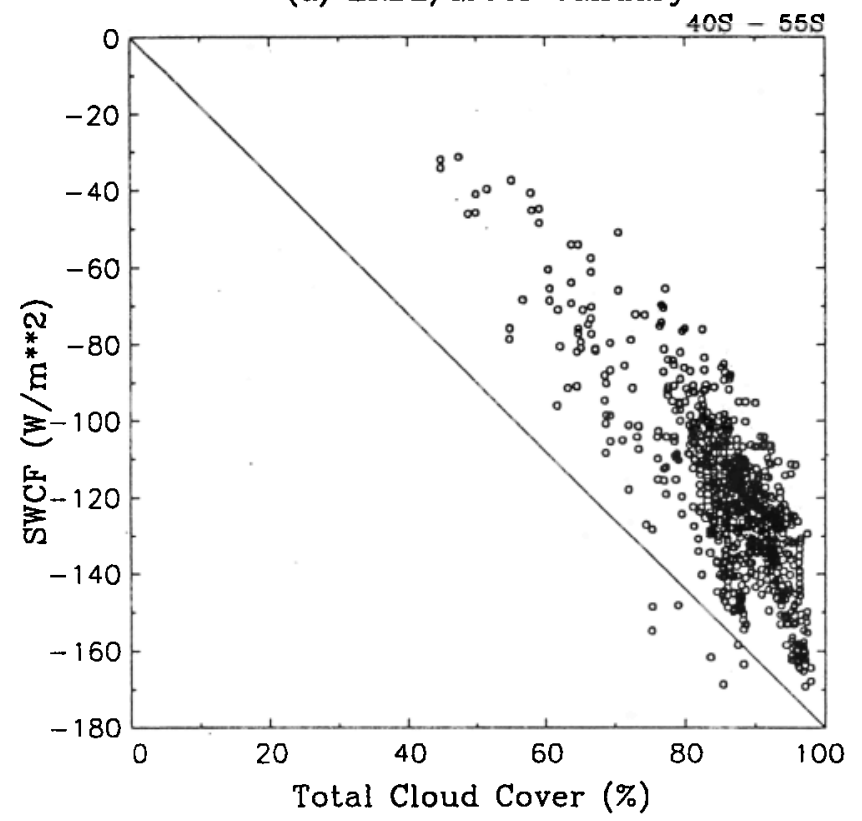

(b) ECHAM4 January

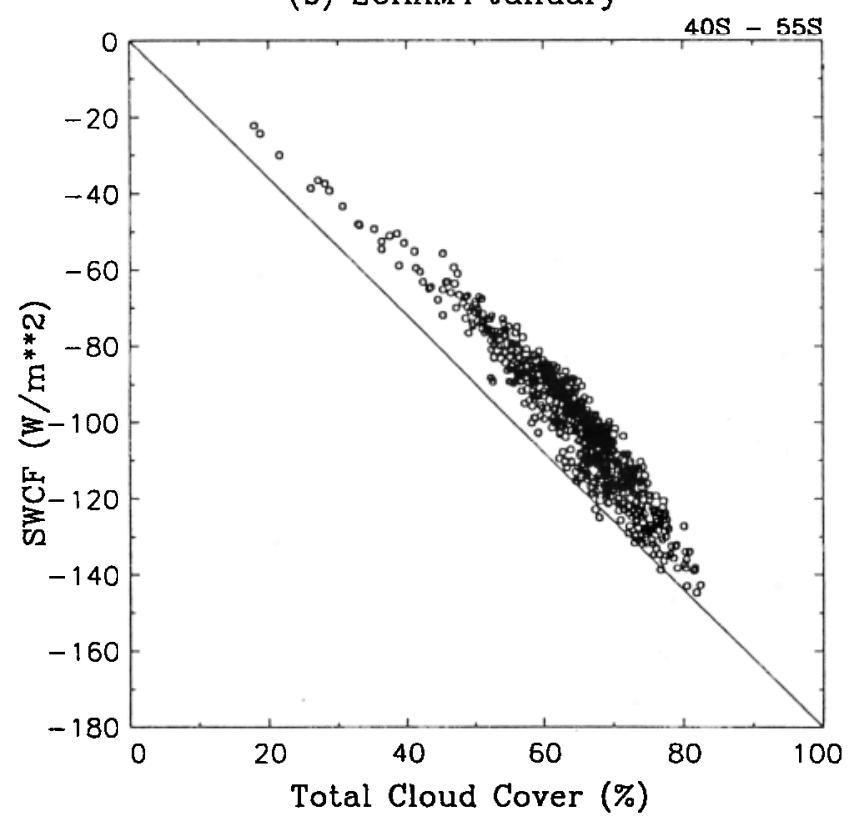

Figure 20. January total cloud cover versus shortwave cloud radiative forcing for the Southern Ocean region $\left(40^{\circ} \mathrm{S}-55^{\circ} \mathrm{S}\right)$ from (a) observations (ERBE and ISCCP) and (b) ECHAM4.

by a lack of low-level clouds), the errors in the tropics are related to the method of calculating grid-averaged radiative fluxes from grid-averaged input data such as cloud water content, in particular. This procedure is crucial for the computation of the shortwave radiative fluxes. As shown by Calahan et al. [1994], for example, the albedo of an optically thick but nonhomogeneous cloud layer is lower than that of a homogeneous cloud with the same cloud water content. Since tropical cloud systems are highly nonhomogeneous in general [Stephens and Greenwald, 1991], the assumption of homogeneity will necessarily introduce a high-albedo bias if compensating errors such as underestimated cloud fraction and/or cloud water con-
ECHAM4 SST anomalies ( $5 \mathrm{~N}-5 \mathrm{~S}$ )

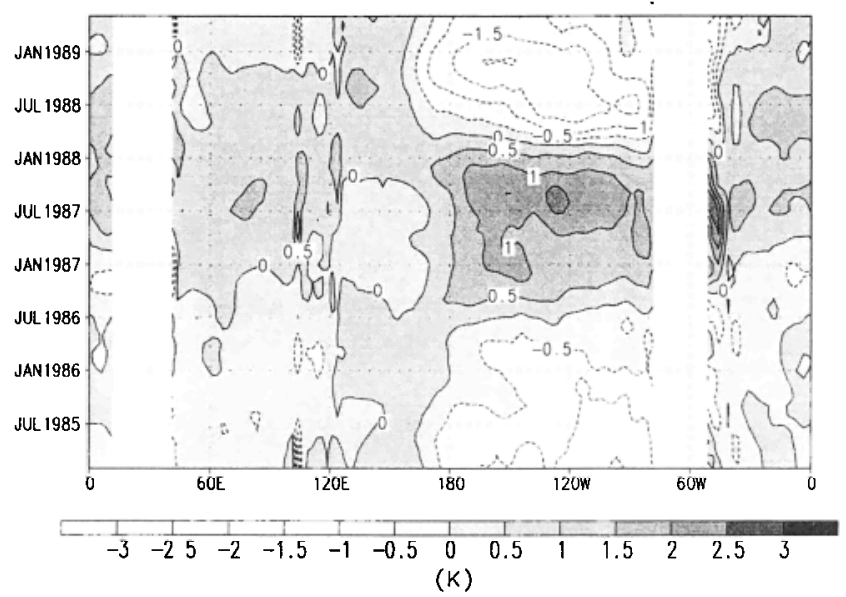

Figure 21. Longitude-time distribution of the equatorial (averaged from $5^{\circ} \mathrm{N}$ to $5^{\circ} \mathrm{S}$ ) sea surface temperature anomalies from the Atmospheric Intercomparison Project data set. Fivemonth running mean is applied.

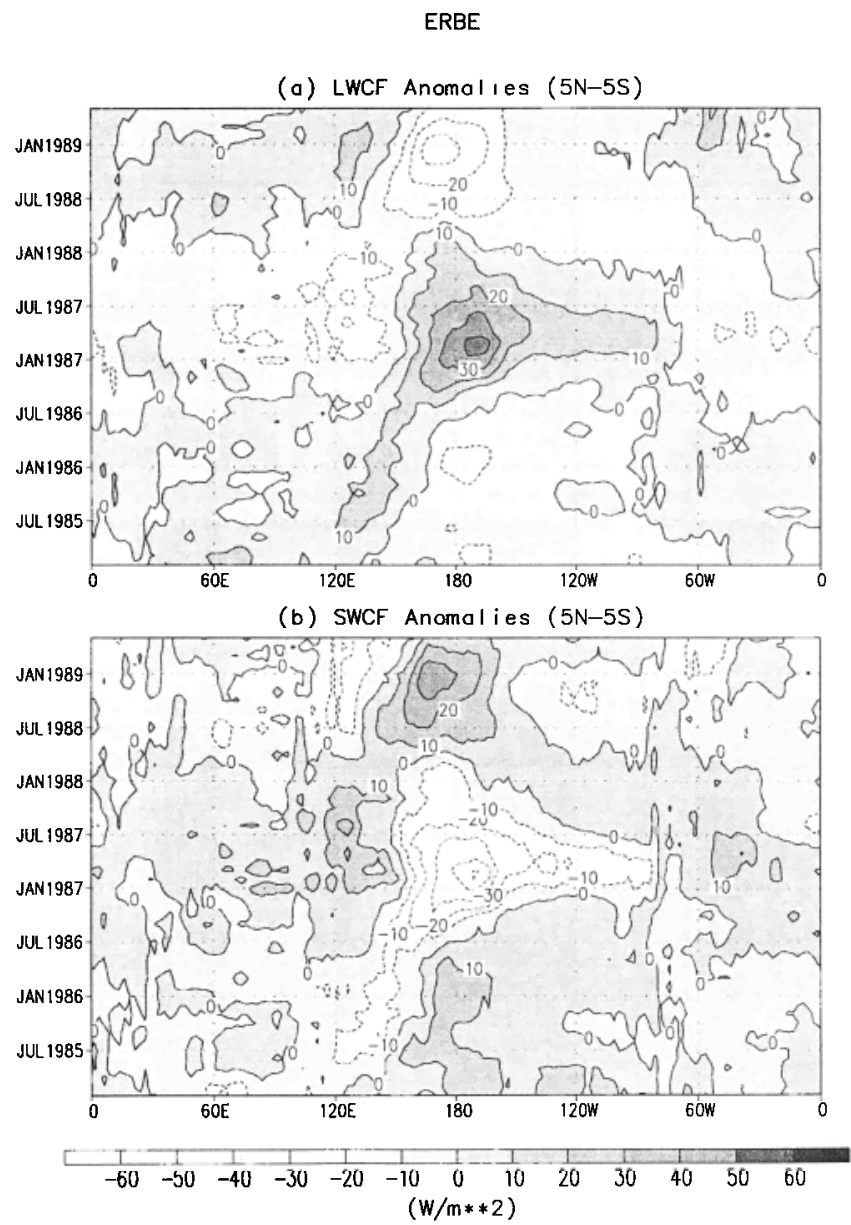

Figure 22. Longitude-time distribution of the equatorial (averaged from $5^{\circ} \mathrm{N}$ to $5^{\circ} \mathrm{S}$ ) (a) longwave cloud radiative forcing anomalies and (b) shortwave cloud radiative forcing anomalies derived from ERBE observations. Five-month running mean is applied. 
ECHAM4

(a) LWCF Anomalies ( $5 \mathrm{~N}-5 \mathrm{~S})$

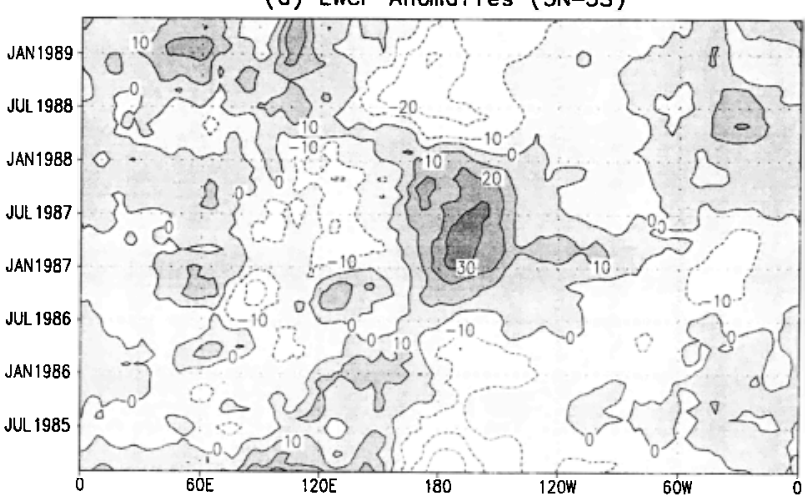

(b) SWCF Anomalies ( $5 \mathrm{~N}-5 \mathrm{~S})$

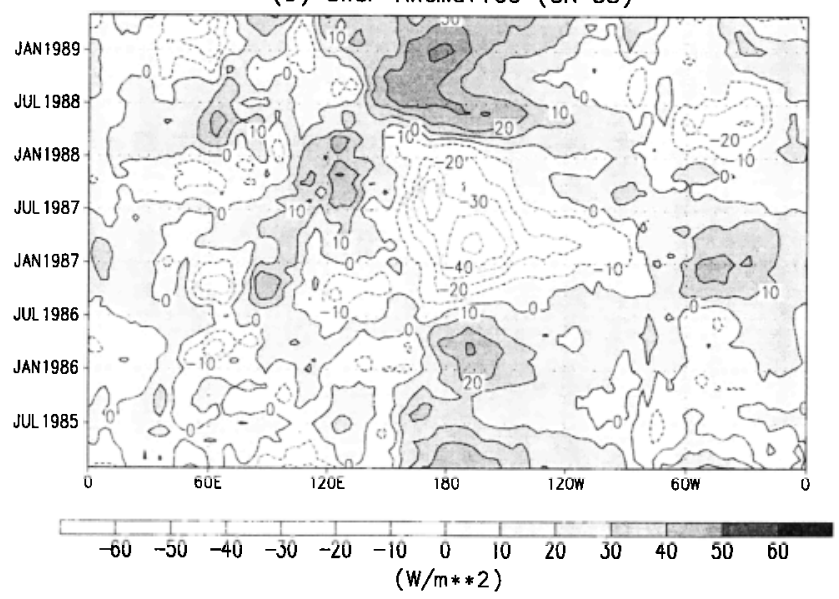

Figure 23. As in Figure 22 except for ECHAM4 cloud radiative forcing anomalies.

tent are excluded. An example of such an error compensation in the ECHAM4 simulation is evident over the tropical continents where both albedo and SWCF are reasonably well captured (because the cloud water content is underestimated,

ISCCP Total Cloud Cover Anomalies (5N-5S)

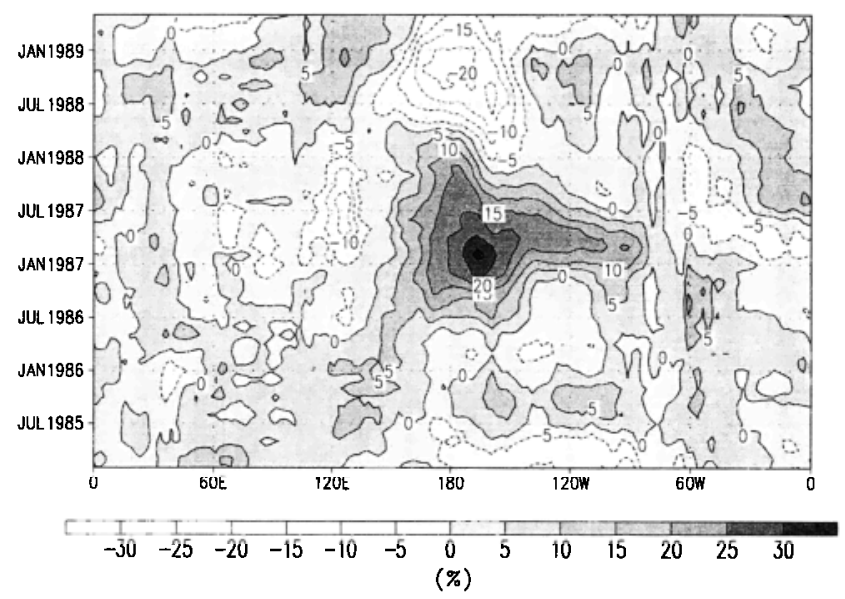

Figure 24. Longitude-time distribution of the equatorial (averaged from $5^{\circ} \mathrm{N}$ to $5^{\circ} \mathrm{S}$ ) total cloud cover anomalies derived from ISCCP data set. Five-month running mean is applied.
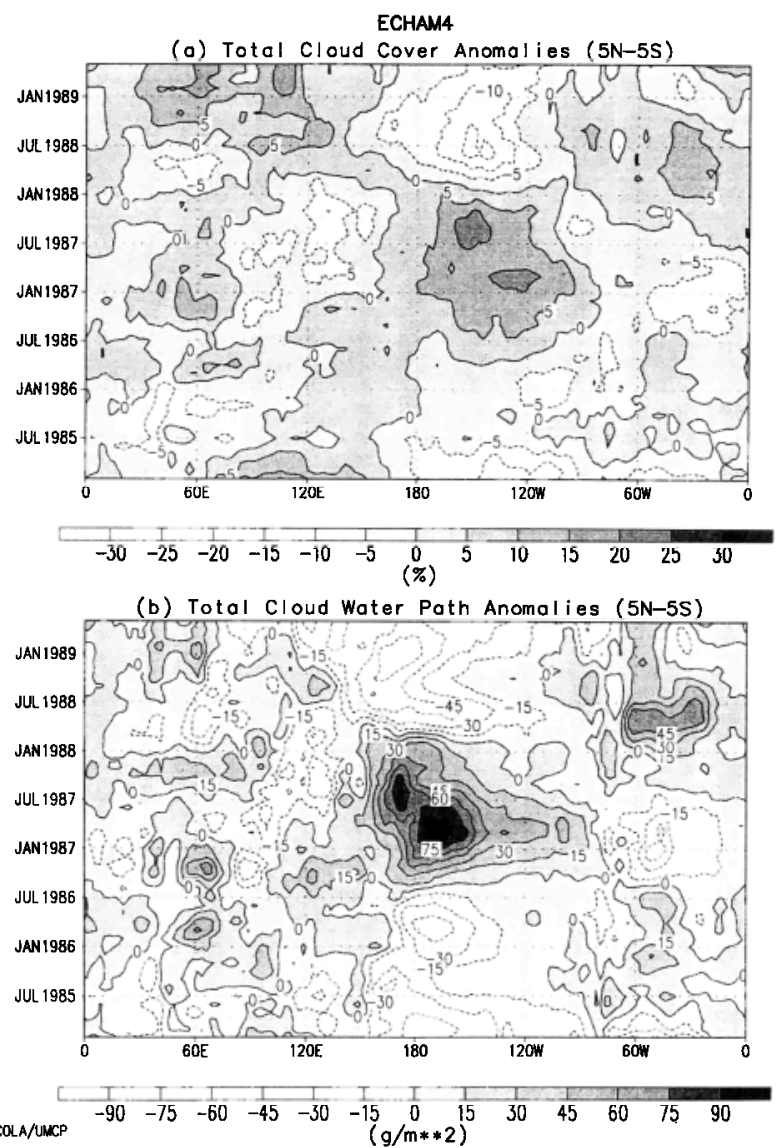

Figure 25. Longitude-time distribution of the equatorial (averaged from $5^{\circ} \mathrm{N}$ to $5^{\circ} \mathrm{S}$ ) (a) total cloud cover anomalies and (b) total cloud water path anomalies derived from ECHAM4 simulation. Five-month running mean is applied.

presumably), while the LWCF is underestimated for that very reason. A more realistic cloud water simulation, on the other hand, would certainly improve the LWCF but deteriorate the SWCF and therefore the surface energy budget and strength of the hydrological cycle. In this case, the underestimate of LWCF appears to be a lesser evil.

In conclusion, in order to improve both components of the cloud radiative forcing, high priority should be devoted to the development of cloud and radiation parameterizations which allow to compute the mean as well as the variance of cloud water, including its effect on radiative transfer.

In addition to an overall good reproduction of the observed mean seasonal cycle the interannual variability of the simulated cloud radiative forcing in the tropics is also in good agreement with ERBE observations. The influence of interannual variations of tropical sea surface temperatures and associated changes of tropical circulation on the cloud radiative forcing is apparent. We also find that the simulated anomalies of shortwave cloud radiative forcing are slightly larger than those revealed in ERBE data. Further analyses suggest that the anomalies found in the model are mostly due to variations in cloud water path and therefore in cloud radiative properties and less connected to the interannual variation in total cloud amount, while the observed anomaly patterns in cloud radiative forcing are closely related to total cloudiness anomalies according to ISCCP data. Insufficient reliability and shortage 
Standard Deviation (1984-1990)

(a) ISCCP Annual Mean Total Cloud Cover

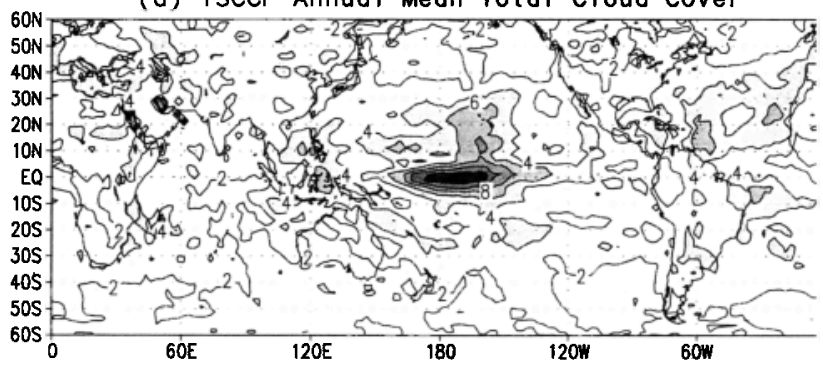

(b) ECHAM4 Annual Mean Total Cloud Cover

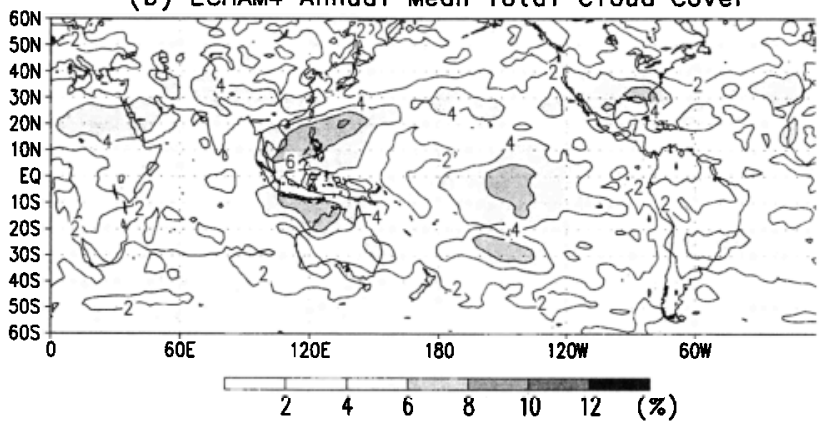

(c) ECHAM4 Annual Mean Total Cloud Woter Path

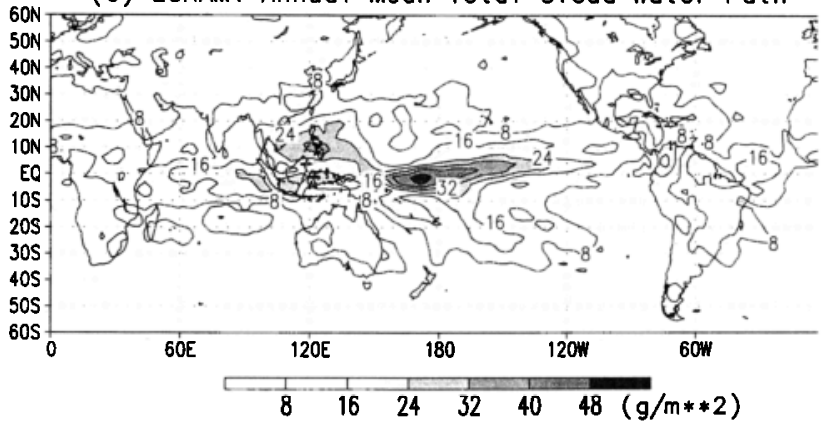

Figure 26. Geographical distribution of the interannual standard deviation of annual mean (a) ISCCP total cloud cover, (b) ECHAM4 total cloud cover, and (c) ECHAM4 total cloud water path. Data from 1984 to 1990 are used to calculate the interannual standard deviation for both ECHAM4 and ISCCP.

in current measurements of cloud vertical distribution and microphysical properties and their radiative effect call for the necessity of a continuous and extended effort in observing and retrieving these quantities. The future operation of moderateresolution imaging spectrometer (MODIS) sensors and cloud and Earth's radiant energy system (CERES) radiometers should enhance our understanding of cloud/radiation processes [Barron et al., 1993] and provide data for a more comprehensive model validation.

Acknowledgment. We thank Lennart Bengtsson for his helpful comments on an earlier version of the paper.

\section{References}

Barkstrom, B. R., The Earth Radiation Budget Experiment (ERBE), Bull. Am. Meteorol. Soc., 65, 1170-1185, 1984.

Barnett, T. P., M. Latif, E. Kirk, and E. Roeckner, On ENSO physics, J. Clim., 4, 487-515, 1991.

Barron, E., and EOS panel on physical climate and hydrology, EOS science priorities for physical climate and hydrology: Key measurements, Global Planet. Change, 7, 253-278, 1993.
Bengtsson, L., K. Arpe, E. Roeckner, and U. Schulzweida, Climate predictability experiments with a general circulation model, Rep. 145, 45 pp., Max-Planck-Inst. für Meteorol., Hamburg, Germany, 1994.

Brinkop, S., and E. Roeckner, Sensitivity of a general circulation model to parameterizations of cloud-turbulence interactions in the atmospheric boundary layer, Tellus, 47A, 197-220, 1995.

Calahan, R. F., W. Ridgway, W. J. Wiscome, and T. L. Bell, The albedo of stratocumulus clouds, J. Atmos. Sci., 51, 2434-2455, 1994.

Cess, R. D., and G. L. Potter, Exploratory studies of cloud radiative forcing with a general circulation model, Tellus, 39A, 460-473, 1987.

Cess, R. D., et al., Intercomparison and interpretation of climate feedback processes in 19 atmospheric general circulation models, $J$. Geophys. Res., 95, 16,601-16,615, 1990.

Cess, R. D., E. F. Harrison, P. Minnis, B. R. Barkstrom, V. Ramanathan, and T. Y. Kwon, Interpretation of seasonal cloud-climate interactions using Earth Radiation Budget Experiment data, J. Geophys. Res., 97, 7613-7617, 1992.

Chen, C.-T., E. Roeckner, and B. J. Soden, A comparison of satellite observations and model simulations of column integrated moisture and upper tropospheric humidity, Rep. 155, 48 pp., Max-Planck-Inst. für Meteorol., Hamburg, Germany, 1995.

Claussen, M., U. Lohmann, E. Roeckner, and U. Schulzweida, A global data set of land-surface parameterization, Rep. 135, $30 \mathrm{pp}$., Max-Planck-Inst. für Meteorol., Hamburg, Germany, 1994.

Davis, A., P. Gabriel, S. Lovejoy, D. Schertzer, and G. L. Austin, Discrete angle radiative transfer, 3, Numerical results and meteorological applications, J. Geophys. Res., 95, 11,729-11,742, 1990.

ERBE Science Team, First data from the Earth Radiation Budget Experiment (ERBE), Bull. Am. Meteorol. Soc., 67, 818-824, 1986.

Fouquart, Y., and B. Bonnel, Computations of solar heating of Earth's atmosphere: A new parameterization, Beitr. Phys. Atmos., 53, 35-62, 1980.

Gates, W. L., AMIP: The atmospheric model intercomparison project, Bull. Am. Meteorol. Soc., 73, 1962-1970, 1992.

Giorgetta, M., and M. Wild, The water vapor continuum and its representation in ECHAM4, Rep. 162, 38 pp., Max-Planck-Inst. für Meteorol., Hamburg, Germany, 1995.

Gurney, R. J., J. L. Foster, and C. L. Parkinson (Eds.), Atlas of Satellite Observations Related to Global Change, 470 pp., Cambridge University Press, New York, 1993.

Harshvardhan, and D. A. Randall, Comments on "The parameterization of radiation for numerical weather prediction and climate models," Mon. Weather Rev., 113, 1832-1833, 1985.

Hartmann, D. L., V. Ramanathan, A. Berroir, and G. E. Hunt, Earth radiation budget data and climate research, Rev. Geophys., 24, 439468,1986

Hense, A., M. Kerschgens, and E. Raschke, An economical method for computing radiative transfer in circulation models, $Q$.J. $R$. Meteorol. Soc., 108, 231-252, 1982.

Heymsfield, A. J., Precipitation development in stratiform ice cloud: A microphysical and dynamical study, J. Atmos. Sci., 34, 367-381, 1977.

Intergovernmental Panel on Climate Change (IPCC), Climate Change: The supplementary Report to the IPCC Scientific Assessment, 200 pp., edited by J. T. Houghton, B. A. Callander, and S. K. Varney, Cambridge University Press, New York, 1992.

Kiehl, J. T., and V. Ramanathan, Comparison of cloud radiative forcing derived from the Earth Radiation Budget Experiment with that simulated by the NCAR community climate model, J. Geophys. Res., $95,11,679-11,698,1990$.

Kiehl, J. T., J. J. Hack, and B. P. Briegleb, The simulated Earth radiation budget of the National Center for Atmospheric Research community climate model CCM2 and comparison with the Earth Radiation Budget Experiment data, J. Geophys. Res., 99, 20,81520,827, 1994.

Klein, S. A., and D. L. Hartmann, Spurious changes in the ISCCP data set, Geophys. Res. Lett., 20, 455-458, 1993.

Lau, N. C., Modeling the seasonal dependence of the atmospheric responses to observed El Niño 1962-1976, Mon. Weather Rev., 113, 1970-1996, 1985.

Lohmann, U., and E. Roeckner, The influence of cirrus cloud-radiative forcing on climate and climate sensitivity in a general circulation model, J. Geophys. Res., 100, 16,305, 1995.

London, J., A study of the atmospheric heat balance, Rep. AFCRCTR57-287, ASTLA 117227, Coll. of Eng., New York Univ., 1957. 
Louis, J. F., A parametric model of vertical eddy fluxes in the atmosphere, Boundary Layer Meteorol., 17, 187-202, 1979.

Matveev, L. T., Cloud Dynamics, 340 pp., D. Reidel, Norwell, Mass., 1984.

McFarlane, N. A., G. J. Boer, J. P. Blanchet, and M. Lazare, The Canadian climate centre second-generation general circulation model and its equilibrium climate, J. Clim., 5, 1013-1044, 1992.

Mokhov, I. I., and M. E. Schlesinger, Analysis of global cloudiness, 2, Comparison of ground-based and satellite-based cloud climatologies, J. Geophys. Res., 99, 17,045-17,065, 1994.

Morcrette, J.-J., Radiation and cloud radiative properties in the European Centre for Medium-Range Weather Forecasts forecasting system, J. Geophys. Res., 96, 9121-9132, 1991.

Nordeng, T. E., Extended versions of the convective parameterization scheme at ECMWF and their impact on the mean and transient activity of the model in the tropics, Q.J.R. Meteorol. Soc., in press, 1995.

Ohring, G., and P. F. Clapp, The effect of changes in cloud amount on the net radiation at the top of the atmosphere, J. Atmos. Sci., 37 $447-454,1980$.

Olson, J. S., J. A. Watts, and L. J. Allison, Carbon in live vegetation of major world ecosystems, Rep. ORNL-5862, Oak Ridge Natl. Lab., Oak Ridge, Tenn., 1983.

Ramanathan, V., The role of Earth radıation budget studies in clımate and general circulation research, J. Geophys. Res., 92, 4075-4095, 1987.

Ramanathan, V., and W. Collins, Thermodynamic regulation of ocean warmıng by cirrus clouds deduced from observation of the $1987 \mathrm{E}$ Niño, Nature, 351, 27-32, 1991

Ramanathan, V., R. D. Cess, E. F. Harrison, P. Minnis, B. R. Barkstrom, E. Ahmad, and D. Hartmann, Cloud-radiative forcing and climate: Insights from the Earth Radiation Budget Experiment, Science, 243, 57-63, 1989.

Rasmussen, E. M., Observational aspects of ENSO cycle teleconnections, in Teleconnections Linking Worldwide Climate Anomalies, edited by M. H. Glantz, R. W. Katz, and N. Nicholls, pp. 309-343, Cambridge University Press, New York, 1991.

Robock, A., The seasonal cycle of snow cover, sea ice, and surface albedo, Mon. Weather Rev., 108, 267-285, 1980.

Rockel, B., E. Raschke, and B. Weyres, A parameterization of broad band radiative transfer properties of water, ice and mixed clouds, Betr. Phys Atmos., 64, 1-12, 1991.

Roeckner, E., M. Rieland, and E. Keup, Modelling of cloud and radiation in the ECHAM model, in ECMWF/WCRP Workshop on "Clouds, Radiative Transfer and the Hydrological Cycle," pp. 199222, Eur. Cent. for Medium-Range Weather Forecasts, Reading, England, 1991

Roeckner, E., et al., Simulation of the present-day climate with the ECHAM model: Impact of model physics and resolution, Rep. 93, 171 pp., Max-Planck-Inst. für Meteorol., Hamburg, Germany, 1992.
Rossow, W. B., and A. A. Lacis, Global, seasonal cloud variation from satellite radiance measurements, II, Cloud properties and radiative effects, J. Clim., 3, 1204-1253, 1990.

Schiffer, R. A., and W. B. Rossow, The International Satellite Cloud Climatology Project (ISCCP) global radiance data set: A new resource for climate research, Bull. Am. Meteorol. Soc., 66, 1498-1505, 1985.

Sherwood, S. C., V. Ramanathan, T. P. Barnett, M. K. Tyree, and E. Roeckner, Response of an atmospheric general circulation model to radiative forcing of tropical clouds, $J$. Geophys. Res., 99, 20,82920,845, 1994.

Stephens, G. L., and T. J. Greenwald, The Earth's radiation budget and its relation to atmospheric hydrology, 2, Observations of cloud effects, J. Geophys. Res., 96, 15,325-15,340, 1991.

Sundquist, H., A parameterization scheme for non-convective conden sation including prediction of cloud water content, Q. J. R. Meteorol. Soc., 104, 677-690, 1978.

Tiedtke, M., A comprehensive mass flux scheme for cumulus parameterization in large scale models, Mon. Weather Rev., 117, 17791800, 1989.

Walcek, C. J., Cloud cover and its relationship to relative humıdity during a springtime midlatıtude cyclone, Mon. Weather Rev., 122, 1021-1035, 1994.

Warren, S. G., C. J. Hahn, J. London, R. M. Chervin, and R. L. Jenne, Global distribution of total cloud cover and cloud type amounts over ocean, $N C A R / T N-317+S T R, 40$ pp., 170 maps, Natl. Cent. for Atmos. Res., Boulder, Colo., 1988

Webster, P. J., The large-scale structure of the tropical atmosphere, in Large-Scale Dynamical Processes in the Atmosphere, edited by B. J. Hoskins and R. Pearce, pp. 235-276, Acad., San Diego, Calif., 1983.

Williamson, D. L., and P. J. Rasch, Two dimensional semi-Lagrangian transport with shape preserving interpolation, Mon. Weather Rev., $117,102-129,1989$.

$\mathrm{Xu}, \mathrm{K}$. M., and S. K. Krueger, Evaluation of cloudiness parameterization using a cumulus ensemble model, Mon. Weather Rev., 119 342-367, 1991.

Zhang, M. H., R. D. Cess, T. Y. Kwon, and M. H Chen, Approaches of comparison for clear-sky radiative fluxes from general circulation models with Earth Radiation Budget Experiment data, J. Geophys. Res., 99, 5515-5523, 1994.

C.-T. Chen, corresponding author, Department of Earth Sciences, National Taiwan Normal University, 88, Section 4, Ting-Chou Road, Taipei 117, Taiwan, R. O. C. (e-mail: chen (t)atms.geos.ntnu.edu.tw) E. Roeckner, Max Planck Institute for Meteorology, $20146 \mathrm{Ham}$ burg, Germany.

(Received June 22, 1995; accepted October 4, 1995.) 